\title{
LOS GRANDES GRUPOS EMPRESARIALES CHINOS: ENTENDIENDO LOS MECANISMOS DEL CAPITALISMO DE ESTADO EN CHINA ${ }^{1}$
}

\author{
WE ARE THE (NATIONAL) CHAMPIONS: UNDERSTANDING THE \\ MECHANISMS OF STATE CAPITALISM IN CHINA
}

\author{
Li-Wen Lin \\ Curtis J. Milhaupt ${ }^{2}$
}

\begin{abstract}
RESUMEN: China ahora es el segundo país que más empresas Global Fortune 500 tiene en el mundo. Casi todas ellas son empresas estatales (SOEs, acrónimo en inglés) organizadas dentro de grandes grupos empresariales, con un organismo central gubernamental denominado SASAC como accionista controlador final. A pesar de la importancia de estos grupos para la economía doméstica china y su estrategia de invertir en el exterior, muchas de las particularidades del sector SOE -especialmente su estructura organizacional y las características de gobierno corporativo de los distintos grupos empresariales- permanecen en la penumbra. Para salir de esa oscuridad se requiere dejar el análisis habitual basado en los costos de agencia de las empresas que cotizan en bolsa, predominante en la bibliografía sobre gobierno corporativo. Por el contrario, examinamos la ecología relacional en la que se mueven los grupos $\mathrm{SOE}$, con atención en los mecanismos institucionalizados que unen los grupos empresariales con otros órganos del Estado-partido. Pensamos que a través de estos enlaces, las élites administradoras de la economía china han ensamblado lo que Mancur Olson llamó una "coalición englobante total" - una organización cuyos miembros deben tanto a la sociedad, lo que hace que tengan grandes incentivos para estar muy pendientes de la productividad del grupo SOE. Exponiendo de esta manera los mecanismos del capitalismo de Estado chino surgen muchas interrogantes para los investigadores y para los responsables de políticas públicas, las que se incrementan a medida que se expande la interacción global de las empresas chinas. Por ejemplo, ¿se explica adecuadamente el ascenso de las SOEs chinas mediante las teorías ordinarias de la bibliografía comparada de gobierno corporativo? ¿Cómo podría transformar la trayec-
\end{abstract}

\footnotetext{
1 We are the (National) Champions: Understanding the Mechanisms of State Capitalism in China. Trad. realizada por el Dr. Marcos José Jaramillo, Profesor de Derecho Chino de la Pontificia Universidad Católica de Chile. Agradecemos especialmente al Dr. Milhaupt que gestionó ante la Stanford Law Review la autorización para efectuar y reproducir la traducción. El artículo original en inglés es: Li-Wen Lin and Curtis J. Milhaupt, "We are the (National) Champions: Understanding the Mechanisms of State Capitalism in China", Stanford Law Review. April 2013, Vol. 65 Issue 4, pp. 697-759. Por razones de espacio, no he colocado ni comentado gráficos ni tablas estadísticas que aparecen en el original.

2 Lin es candidata a Doctora en el Departamento de Sociología de la Universidad de Columbia y Doctora en Derecho por la Universidad de Illinois (Urbana-Champaign). Milhaupt es Titular de la Cátedra Parker de Derecho Comparado en Derecho de Sociedades y Titular de la Cátedra Fuyo de Derecho Japonés de la Facultad de Derecho de la Universidad de Columbia. Hemos recibido valiosos comentarios a un borrador de este artículo de parte de Yuen Ang, Donald Clarke, Robert Ferguson, Ronald Gilson, Jeffrey Gordon, Nicholas Howson, Sung-Yong Kim, Benjamin Liebman, Mariana Pargendler, Hugh Patrick, Randall Peerenboom, Frank Upham y de los participantes en los talleres de trabajo en Pekín y Seúl, y en la facultades de derecho de la universidades de Columbia, Cornell, Fordham, NYU y Vanderbilt. Agradecemos también a los entrevistados del ámbito de negocios, gobierno y academia en Pekín, quienes generosamente compartieron su conocimiento y visión con nosotros. Las entrevistas fueron realizadas en forma anónima.
} 


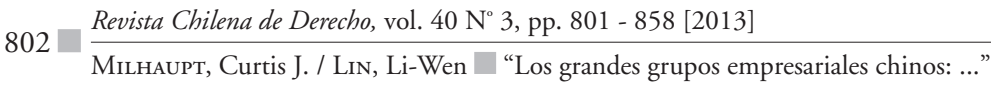

toria institucional del capitalismo corporativo en China la cada vez mayor operación de las SOEs en el extranjero? ¿Las instituciones regulatorias del mercado y de las inversiones en Estados Unidos consideran adecuadamente a actores híbridos de negocios y política como son las SOEs chinas? Examinando la estructura organizativa de las SOEs, este artículo entrega los cimientos para futuras investigaciones sobre un aspecto esencial de la política económica contemporánea de China.

Palabras clave: Grupos empresariales, derecho de empresas, gobierno corporativo.

ABSTRACT: China now has the second largest number of Global Fortune 500 Companies in the world. Most of these are state-owned enterprises (SOEs) organized into massive corporate groups with a central government agency known as SASAC as their ultimate controlling shareholder. Despite their importance to China's domestic economy and outward investment strategy, many features of the SOE sector -particularly the organizational structure and governance characteristics of the SOE groups- remain a black box. Unpacking the black box requires moving away from the standard focus on agency costs in listed firms that predominates in the corporate governance literature. Instead, we examine the relational ecology in which the SOE groups exist, with a focus on institutionalized mechanisms linking the business groups with other organs of the party-state. We argue that through these linkages, Chinese managerial elites in the economy have assembled what Mancur Olson called an "encompassing organization" - a coalition whose members own so much of society that they have important incentives to be actively concerned about how productive it is.

EXPOSING the mechanisms of Chinese state capitalism in this way raises many questions for scholars and policymakers, the salience of which increases as the global interaction of Chinese firms expands: For example, is the rise of Chinese SOEs adequately explained by prevailing theories in the comparative corporate governance literature? How might the increased operation of Chinese SOEs in foreign markets change the institutional trajectory of corporate capitalism in China? Do the institutions of market and investment regulation in the U.S. adequately contemplate hybrid business-political actors like Chinese SOEs? By examining the organizational structure of SOEs, the Article provides a foundation for future research on a pivotal aspect of China's contemporary political economy.

Key words: Corporate groups, corporate law, corporate governance.

\section{INTRODUCCIÓN}

El ascenso de China como poder económico global plantea una inmensa cantidad de desafíos para los especialistas en gobierno corporativo comparado. Mientras China parece mostrarnos una nueva variedad de capitalismo, frecuentemente calificado como "capitalismo de estado", las características e implicancias de este sistema son todavía muy poco comprendidas ${ }^{3}$. Particularmente debido a que el sistema económico chino pareciese estar en sus primeras etapas de desarrollo, entender el mecanismo por el cual opera el capitalismo de es-

\footnotetext{
3 Como un comentarista señala, "habiéndose apropiado del capitalismo occidental y reflejando muchas de sus características superficiales, China hoy plantea un desafío profundo y sin precedentes a ese tipo de capitalismo, que los académicos y responsables de formular políticas gubernamentales están recién comenzando a captar”. Meyer (2011) p. 8.
} 
tado en la actualidad y cómo puede cambiar a medida que las empresas chinas se globalizan es una tarea urgente para los investigadores.

Una de las características más propias del capitalismo de estado en China es el rol crucial de alrededor de 100 grandes empresas estatales (SOEs) (guoyou qiye) controladas por organismos del gobierno nacional en industrias de vital importancia tales como las del acero, telecomunicaciones y transportes. Aunque pocas de esas compañías, como Sinopec y China Mobile, tienen nombres conocidos en occidente, el sector estatal domina importantes industrias en China y es cada vez más activo en los mercados globales. Como The Economist recientemente lo señalaba, "a medida que año a año la economía crece a tasas de doble dígito, grandes empresas estatales están subiendo en las tablas mundiales de clasificación de sociedades en cada sector empresarial desde el petrolero al bancario" ${ }^{4}$. China tiene ahora la segunda más alta concentración de empresas de la lista Fortune Global 500 (setenta y tres) de las empresas más grandes del mundo 5 , y el número de empresas chinas en la lista ha crecido en promedio a una tasa anual de aproximadamente $25 \%$ desde $2005^{6}$. Estas SOEs de importancia mundial son los grupos nacionales de China.

Más de la mitad de las empresas chinas señaladas en el Fortune Global 500 de 2012 son empresas estatales supervisadas por un órgano del gobierno central ${ }^{7}$. Excluyendo los grandes bancos ${ }^{8}$ y compañías de seguros, el poder controlador sobre las sociedades más grandes e importantes, presumiblemente en nombre de los ciudadanos chinos, pertenece a una sociedad holding conocida como Comisión Supervisora y Administradora de Activos Estatales, o SASAC (State-Owned Assets Supervision and Administration Commission, su acrónimo en inglés), la que ha sido descrita como "el accionista controlador más grande del mundo" 9 . A pesar de que las selectas compañías que sirven de cara externa a las empresas estatales chinas (pensar en Sinopec o China Mobile) son cotizadas en las bolsas de Shanghai, Hong Kong u otros centros financieros mundiales, ellas están alojadas dentro de grupos integrados verticalmente. El accionista mayoritario de cada compañía es la sociedad matriz del grupo -la que a su vez pertenece en un 100\% a SASAC-. La sociedad matriz

\footnotetext{
4 The EConomist (2011b) p. 79.

5 CNN (2012) clasificando a China en segundo lugar detrás de Estados Unidos en número de empresas en la lista de Fortune 2012 de las sociedades más grandes del mundo según utilidades; CNN (2011) clasificando a Japón en segundo lugar detrás de Estados Unidos, y China en tercer lugar, en la lista de Fortune Global 5002011.

${ }^{6}$ CNN (2012) enumerando 73 empresas chinas en la lista Fortune Global 500 200; CNN (2005) enumerando 16 empresas chinas en la lista de 2005.

7 Comisión Supervisora y Administradora de Activos Estatales del Consejo de Estado, Central SOEs. Disponible en: <http://www.sasac.gov.cn/n2963340/n2971121/n4956567/4956583.html (fecha de consulta: 23 de marzo de 2013)>. Muchas otras empresas chinas del Fortune Global 500 son SOEs controladas por gobiernos provinciales o locales.

${ }^{8}$ Los llamados "bancos transformados en sociedades anónimas" son en su mayoría de propiedad de otras agencias del Estado y son supervisados por la Comisión China Reguladora de Bancos y por el Banco Chino del Pueblo. MarTin (2012) p. 8. En cambio, los "bancos comerciales constituidos como sociedades anónimas" "tienen una mezcla de estructuras de propiedad" que puede incluir grandes porcentajes de propiedad de agencias del Estado como también de parte de compañías controladas por SASAC. Véase por ejemplo, China Bohai BAnk Co., Ltd. (2010) p. 6 (en que se enumera a tres sociedades de SASAC en la lista de siete accionistas del Bohai Bank).

9 Aguiar et al. (2007). Las características distintivas de SASAC como accionista controlador son analizadas más adelante en la Parte III.
} 
coordina las actividades del grupo y transmite las directrices de negocios a sus miembros, los que están obligados contractualmente a promover las políticas del estado. Cada grupo empresarial está conectado frecuentemente a través de propiedad accionaria y de alianzas contractuales a otros grupos en la misma industria o en otras complementarias, otros grupos empresariales a nivel provincial e incluso a instituciones estatales no económicas tales como las universidades ${ }^{10}$. Los altos ejecutivos de las grandes empresas estatales tienen simultáneamente cargos importantes en el gobierno y en el partido comunista.

Aunque el esquema básico de este sistema es ampliamente conocido, el concepto de capitalismo de estado en China en muchos aspectos -particularmente la estructura organizacional y el régimen de gobierno corporativo que rodea a estas grandes empresas estatales- es materia desconocida ${ }^{11}$. Los investigadores han explorado numerosas facetas de la inversión, control y organización de las sociedades occidentales, pero en relación con las empresas chinas, la investigación está solo en los primeros pasos de la "propiedad estatal”: ¿Cómo pudieron transformarse unas empresas estatales fallidas en jugadores a escala global y qué modelos extranjeros miraron los planificadores chinos para inspirarse? ¿Cómo están relacionadas las sociedades nacionales importantes y ellas respecto de sus fuentes de financiamiento?¿Qué vincula a las grandes empresas estatales con las instituciones del gobierno y del partido comunista? ¿Qué estructuras de incentivos operan dentro de este sistema? ¿Cómo se comporta el Estado-partido (comunista) en su rol de accionista controlador? ¿Cuáles son las implicancias de este sistema para nuestra comprensión del gobierno corporativo en China y para la potencial transformación futura del capitalismo corporativo chino?

Los estudios hechos hasta la fecha solo han dado respuestas fragmentarias a dichas preguntas. En parte, se debe a la escasez de datos confiables, pero también a la manera en que los investigadores se han aproximado al problema ${ }^{12}$. Casi todos los estudiosos del gobierno corporativo chino, por ejemplo, han tomado la sociedad individual -la sociedad que cotiza en bolsa- como la unidad de análisis, aun cuando los grupos empresariales son omnipresentes en el sector estatal y la empresa que cotiza en bolsa es solo una parte de una compleja red de sociedades y relaciones que caracterizan el capitalismo de Estado chino ${ }^{13}$. Más aún, los investigadores frecuentemente comienzan y terminan sus análisis comparando las características del gobierno corporativo de las empresas chinas que cotizan en bolsa con

\footnotetext{
10 Véase Parte II.

11 El desconocimiento perpetúa amplias generalizaciones que obscurecen el mecanismo dentro del sistema. Considere la siguiente caracterización: "China es el actor principal del capitalismo de estado, un sistema en el que los gobiernos usan las empresas estatales y los vehículos de inversión para dominar la actividad del mercado. La primera diferencia entre esta forma de capitalismo y la occidental, con su variedad dirigida por el mercado, es que las decisiones sobre cómo valorar los activos y cómo asignar los recursos son hechas por funcionarios políticos (no por las fuerzas del mercado) con fines políticos en mente”. Bremmer y STEWART (2010).

12 Este fenómeno de ninguna manera es único a China. Durante el ascenso económico de Japón, los investigadores trabajando dentro de la tradición estadounidense tenían unas “anteojeras” teóricas que obstruían su entendimiento sobre las estructuras corporativas japonesas y sus instituciones económicas. GiLson y RoE (1993) pp. 871, 881, 905. Véase citas 22-23.

13 La inadvertencia es desconcertante debido a que muchos investigadores del gobierno corporativo son juristas y el grupo empresarial es un concepto legal en China. Véase cita 52 y Parte II.A.3.
} 
los estándares e instituciones globales (que típicamente significan los de Estados Unidos). Esta perspectiva, seguramente, produce percepciones interesantes, pero enfoca invariablemente la atención del analista en lo que le falta al sistema chino, pero no en cómo está construido ni en cómo funciona. Creemos que, como fue el caso con los estudios sobre el gobierno corporativo japonés en los años $90^{14}$, vendrá un verdadero avance en la comprensión del capitalismo estilo chino si lo analizamos en sus propios términos, en vez de hacerlo principalmente en referencia a algo que no es.

En este artículo, exploramos los mecanismos del capitalismo de estado en China analizando el particular sistema de organización industrial en el que fueron reunidas y en el que funcionan las grandes empresas estatales del país. Para ayudar la investigación, ampliamos nuestro foco más allá de la típica preocupación del gobierno corporativo con las relaciones de agencia, tratando de entender la ecología relacional que fomenta la producción en un sistema donde todos los caminos llegan finalmente al Estado-partido. Con este propósito presentamos dos simples conceptos: Jerarquía interconectada es nuestro término para señalar las características del gobierno corporativo desde arriba hacia abajo dentro de los grupos empresariales, individualmente considerados, que están unidos mediante profundos vínculos a otras instituciones controladas por el Estado. Puente institucional es el término que utilizamos para referirnos al amplio uso de sistemas de rotación de personal, estructuras vinculadas de propiedad accionaria y formas estratégicas de cooperación, tales como las empresas conjuntas (joint ventures), que sirven para unir componentes separados del sector estatal. Estos mecanismos crean redes entre los negocios y otros órganos del Estado-partido, promueven el flujo de la información, y proveen incentivos de alto poder hacia los actores del sistema por medio de la unión entre el rendimiento de la empresa y el progreso político. Todas juntas, estas características pueden ser pensadas como medios para componer lo que Mancur Olson llamó una "coalición englobante total” -o sea aquella en la que cuyos miembros "deben tanto a la sociedad de manera que tienen grandes incentivos para estar muy pendientes de su productividad"15-.

Aunque en la economía china hay mucho más que las grandes empresas estatales ${ }^{16}$, existen buenas razones para examinar la ecología institucional en la que funcionan estas SOEs. Según varios indicadores, el sector estatal es una parte significativa de la economía nacional ${ }^{17}$. Quizás más importante todavía para nuestros propósitos, como la doctrina re-

\footnotetext{
14 Véase citas 21-23.

15 Olson (1982) p. 48.

16 Para el argumento que señala que el éxito de la economía china está en el capitalismo "bambú” (empresarial) y no en el capitalismo de estado, véase The Economist (2011a) p. 13. Para otros trabajos que enfatizan la empresa privada en China, véase en términos generales, por ejemplo, HuAng (2008); Tsai (2002).

17 En 2011, más del 60\% (310) de las más grandes 500 empresas (y todas las más grandes 30 empresas) en China eran SOEs, con activos totales de US\$13,43 trillones y utilidades de 0,3 trillones de yuanes. Véase comunicado de prensa, China Enterprise Confederation/China Enterprise Directors Association, en Liu (2012). Sin embargo, con solo 9,36 millones de trabajadores en 2009, la participación de las SOEs nacionales en el empleo total es muy baja. Véase SASAC (2010b) p. 91. Conocer el tamaño del sector estatal chino no es fácil, con variantes en las estimaciones. Un informe de la OCDE, utilizando información de 2006, estimaba que la participación de las SOEs en el PIB era del 30\%. Véase OCDE (2009) p. 6. Recientemente, una comisión del Congreso de Estados Unidos estimó la participación estatal observable es cercana al 40\%. Véase United STATES
} 
ciente lo ha señalado, "sorprendentemente las SOEs (en todas partes) permanecen poco estudiadas"18. Las SOEs chinas más importantes son ya parte de los listados de las empresas más grandes del mundo y claramente por sí solas son dignas de una profunda investigación. Las grandes empresas estatales son la expresión más acabada del capitalismo de estado en China, la cara globalizada de "China S.A." Es imposible comprender en su totalidad las características institucionales de la economía china si no examinamos a sus actores centrales. El que las compañías sean grandes, como se señala en la lista Fortune Global 500, no implica necesariamente eficiencia o capacidad innovadora, rasgos que serán cruciales para el éxito a largo plazo de las grandes empresas estatales en la economía global. Pero la aparición de grandes SOEs chinas como importantes actores domésticos y globales tiene enormes implicancias en una serie de dimensiones ${ }^{19}$. Además, debido a la etapa relativamente temprana de desarrollo del capitalismo chino, una investigación profunda de sus empresas más grandes y políticamente más conectadas podría darnos perspectivas sobre cómo el sistema dirigido por el Estado podría evolucionar con el tiempo -o al menos sugerir cuáles de las características del actual sistema son susceptibles de cambio y sus posibles direcciones ${ }^{20}-$.

Habiendo definido nuestro trabajo en comprender el concepto borroso del capitalismo de estado chino, nos enfocamos necesariamente en las grandes SOEs con las más estrechas conexiones al Estado-partido en sus variadas manifestaciones institucionales $-\mathrm{o}$ sea, los aproximadamente 100 grupos SOE con sociedades matrices controladas por SASAC a nivel nacional ${ }^{21}$-. Nuestro foco analítico no es un intento de demostrar las ventajas comparativas de la propiedad estatal de la empresa; o de señalar a las grandes empresas estatales como paradigmas de eficiencia, innovación o buen gobierno corporativo; o mostrar que el sector estatal es más importante que el sector privado para el desarrollo de la economía china. Además, como con cualquier relato estilizado, el nuestro a veces sacrifica pequeños detalles con la esperanza de ganar una perspectiva conceptual. El capitalismo de estado

- China Economic and Security Review Commission (2011) pp. 43-44. (que cita a Szamosszegi \& Kyle (2011). Estas estimaciones incluyen SOEs de rango provincial además de las SOEs de rango nacional, siendo estas últimas las que están en el enfoque de este artículo. Véase Szamosszegi \& Krle (2011) p. 7.

18 Pargendler (2012) pp. 2917, 2973.

19 Una lista no exhaustiva de estas implicancias incluye: las dinámicas de que se es "demasiado grande para fallar", poder monopólico, poder blando (soft power) global chino, posibles externalidades negativas generadas por malas prácticas de gobierno corporativo y asignación de recursos.

20 Puede ser instructivo comparar las instituciones del capitalismo corporativo de Estados Unidos en los siglos XIX y XXI para considerar la trayectoria institucional china del futuro. El sistema existente en la actualidad en Estados Unidos - desde las estructuras de propiedad de la sociedad al cúmulo de instituciones regulatorias y de mercado que la rodea- surgieron finalmente de la época del "barón ladrón” (robber baron). Tres aspectos de la experiencia estadounidense parecen ser relevantes para China. Primero, el sistema chino actual del capitalismo de las grandes empresas estatales tiene alguna similitud con la época del "barón ladrón” de Estados Unidos: una economía dominada por grandes conglomerados políticamente bien conectados operando en un débil ambiente institucional sin un escrutinio antimonopólico. Segundo, muestra que un gran cambio en el capitalismo corporativo puede ocurrir en un período de varias décadas. Tercero, sirve de recordatorio que las grandes empresas ejercen una tremenda influencia en las estructuras sociales, políticas e institucionales que las rodean y en las que operan. Para esclarecedoras discusiones de la experiencia histórica estadounidense, véase, por ejemplo, Roy (1997); SKLAR (1988).

${ }^{21}$ Hay también grupos SOE provinciales, supervisados por el nivel provincial de SASAC, y SOEs controladas por los gobiernos de las grandes ciudades, tales como Pekín y Shanghai. 
chino, en su operación, es probablemente más conflictivo y heterogéneo, y menos unido internamente, que lo que nuestro relato pudiese insinuar.

El artículo tiene cuatro partes. Empezamos en la Parte I entregando algunos antecedentes conceptuales para el estudio de las SOEs chinas y brevemente seguir el desarrollo de los grupos empresariales hasta el presente. En la Parte II clarificamos los componentes claves y las principales características organizacionales de los grupos empresariales nacionales y contrastamos ciertas características de los grupos chinos con los de Japón y Corea del Sur, los que han servido de modelos a los planificadores económicos en los años 90. En la Parte III, analizamos el comportamiento de SASAC como accionista controlador dentro de las instituciones más grandes del Estado-partido. En la Parte IV, exploramos las implicancias de nuestro análisis tanto para la doctrina comparativa del sistema corporativo chino como para la futura evolución de la variedad china del capitalismo, particularmente en vista a una creciente actividad global de sus grandes empresas estatales. También examinamos brevemente las implicancias del capitalismo de las grandes empresas estatales chinas para el sistema legal de Estados Unidos.

\section{ENTENDIENDO LA ORGANIZACIÓN INDUSTRIAL CHINA}

\section{A. INTRODUCCIÓN}

Dos décadas de estudios de gobierno corporativo comparado nos han mostrado que las formas exitosas de capitalismo corporativo no tienen características idénticas en los diversos países del mundo. Por el contrario, las compañías difieren sistemáticamente en sus estructuras de propiedad, fuentes de financiamiento y el grupo de instituciones nacionales legales y del mercado que las rodean y en las que se desarrollan ${ }^{22}$. La chispa que encendió esta perspectiva, ahora ya tan estudiada como para que parezca prosaico en retrospectiva, fue el fenomenal ascenso económico de otro país de Asia del Este -Japón- en los años 80. Hace dos décadas, los investigadores reconocían que aunque las empresas japonesas eran globalmente competitivas, sus estructuras de propiedad, sus modelos de financiamiento y sus reglas de gobierno corporativo tenían muy poca semejanza exterior con las sociedades estadounidenses que cotizaban en bolsa, cuyas características se daban por hecho como el punto natural de llegada de un proceso evolucionario en la formación de la sociedad anónima "moderna" 23 .

Hoy, el mundo está nuevamente frente a un sistema económico distinto y globalmente importante procedente de Asia del Este cuyas características aparecen opacas e incluso amenazantes para los no especialistas ${ }^{24}$. Aunque el sistema económico de China ya tiene

\footnotetext{
22 Esta perspectiva básica generó una bibliografía relacionada sobre las "variedades del capitalismo." El estudio fundacional contrasta "economías liberales de mercado," como la de Estados Unidos, con las "economías coordinadas de mercado,” como las de Japón y Alemania. Véase en términos generales Hall y Soskice (2001).

23 La referencia estándar sobre el ascenso de la empresa moderna es Berle y MeAns (1932). Véase también Roe (1994) (que expone la contingencia histórica y política de las estructuras del gobierno corporativo en Estados Unidos analizado a través de Berle y Means).

24 Un análisis de las audiencias ante el Congreso de Estados Unidos tanto en los años 80 como en la década del 2000 nos sugiere que hoy los legisladores estadounidenses tienen muchas de las mismas preguntas y ansiedades
} 
un apelativo, todavía hay mucho trabajo por hacer para entender cómo se organiza el "capitalismo de estado". Como con en el caso de Japón en los años 80, casi toda la bibliografía sobre gobierno corporativo chino se preocupa de los costos de agencia y de seguir a las empresas que cotizan en bolsa. En efecto, la observación de hace 20 años de Ronald Gilson y Mark Roe sobre el obstáculo intelectual para entender la organización industrial japonesa es apropiada en relación con China: "Ver el sistema japonés a través de la mirada de BerleMeans, en la creencia que refleja solamente un esfuerzo de tender un puente a la separación de propiedad y control, causará que no lo comprendamos, y como resultado, perder las lecciones que el análisis comparativo nos ofrezca" 25 .

De manera similar a la forma en que la primera bibliografía sobre Japón buscó localizar al "supervisor que faltaba" en el régimen del banco principal2 ${ }^{26}$, muchos analistas del capitalismo corporativo chino se han enfocado exclusivamente en los problemas de agencia de las compañías que cotizan en bolsa ${ }^{27}$. La búsqueda de soluciones ha llevado a que la mayoría de los comentaristas hayan ido por el camino de la lógica del gobierno corporativo de Estados Unidos, con un enfoque en los directores independientes, el mercado para el control corporativo y una fuerte regulación de los valores de comercio. Este punto de vista genera una larga lista de instituciones formales (predominantemente al estilo de Estados Unidos) cuyo desarrollo se ha determinado como crucial para la transformación futura y la mejora del gobierno corporativo chino $^{28}$. Sin embargo, esto deja largamente inexplorado un enigma en el corazón del capitalismo chino contemporáneo: ¿cómo puede existir un sistema, sin una multitud de instituciones formales que se suponen importantes para las empresas occidentales, que esté produciendo una lista en rápido crecimiento de sociedades en el Fortune Global 500 y que al mismo tiempo esté sosteniendo altos y sostenidos niveles de desarrollo económico en China?

Algunos comentaristas sostienen que dichas "relaciones" son la clave del éxito de la economía china ${ }^{29}$. Esto es casi ciertamente una exacta observación, y los investigadores han avanzado al exponer esas relaciones ${ }^{30}$. Pero queda mucho trabajo por hacer en examinar la naturaleza precisa y función de las relaciones que sostienen el gobierno corporativo chino y el desarrollo económico, particularmente en ausencia de sólidas instituciones legales. Como uno de nosotros ha expuesto en un trabajo conjunto con Ronald Gilson, "unos resultados comerciales estimulados por el gobierno" bajo un régimen político autoritario acostumbrado a los incentivos pueden estar haciendo el trabajo de las instituciones legales formales en

sobre las empresas y la política industrial gubernamental de China como las tenían con respecto a Japón hace dos décadas. Véase Milhaupt (2009) p. 185.

25 Gilson y Roe (1993) p. 881.

26 ShEARD (1989) p. 399.

27 Un ejemplo de este acercamiento es HuAng (2008) pp. 361, 386-388.

28 Para unos reveladores análisis del gobierno corporativo chino dentro del paradigma de costos de agencia, véase, por ejemplo, Clarke (2008) p. 168; TANG (2008) p. 141.

29 Véase, por ejemplo, Allen et al. (2005) pp. 57, 96-97.

30 Un pequeño número de investigadores occidentales se ha enfocado en los grupos empresariales chinos. Véase, por ejemplo, Keister (1998) p. 404; Keister (2009) p. 1709. Un caso excepcional de un estudio de gobierno corporativo chino enfocado en las estructuras del Partido comunista y su influencia en las normas de derecho corporativo es Howson (2009) p. 123. 
la economía china, permitiendo que el comercio a pequeña escala basado en la reputación crezca a niveles donde la entrada a la economía global se hace posible ${ }^{31}$. Y como lo sugerimos allá, los grupos empresariales promovidos por el régimen político y profundamente entrelazados con los dirigentes del partido comunista pueden ser fundamentales para el desarrollo exitoso del régimen ${ }^{32}$.

Este artículo es un intento de investigar más profundamente dentro de la estructura y la ecología organizacional de los grupos empresariales que se encuentran al centro del sistema chino de capitalismo de estado. Nuestra explicación trata de descubrir los mecanismos subyacentes en la naturaleza excepcionalmente englobante de la organización industrial china y su interés no solo está con el gobierno corporativo, sino que también con la producción, transmisión e implementación de políticas industriales, y la maximización del bien del Estado, al menos como es interpretado por la élite dentro del sistema ${ }^{33}$.

\section{B. La Organización Industrial China como una Jerarquía Interconectada}

El capitalismo de estado chino tiene una arquitectura extraordinariamente compleja. Antes de examinar los detalles será útil tener una vista completa del edificio. En esta parte, desarrollamos un modelo simplificado y estilizado de organización industrial china en relación con importantes empresas nacionales y los grupos empresariales en las que están articuladas. Identificamos los componentes principales de los grupos e ilustramos gráficamente sus conexiones. Habiendo esbozado los contornos del sistema, retrocedemos un paso para brevemente localizar sus orígenes.

\section{Una simple construcción analítica}

Como se ha señalado, creemos que una perspectiva de agencia-costos en las empresas que cotizan en bolsa no capta aspectos esenciales del gobierno corporativo y la organización industrial de China. Para ampliar nuestro lente analítico, introducimos dos conceptos simples y originales. Nosotros llamamos jerarquía interconectada a la estructura organizacional del capitalismo de estado chino. Este término capta una característica principal de ese diseño de organización industrial: grupos de sociedades verticalmente integrados y organizados bajo SASAC, con conexiones estratégicas tanto con otros grupos empresariales como con órganos gubernamentales e instituciones estatales, tales como las universidades, intrincados

31 Gilson y Milhaupt (2011) pp. 227, 239, 261-262.

32 Gilson y Milhaupt (2011) pp. 262, 276.

33 Tomando como unidad de análisis al grupo más que a las empresas individualmente consideradas produce perspectivas inmediatas. Una faceta destacada de la agrupación de empresas en China -y hasta la fecha completamente inexplorada- es que se trata de un concepto legal: los grupos empresariales deben registrarse con el Estado para gozar de las ventajas de tal afiliación, y las sociedades están vinculadas unas con otras por un acuerdo jurídico llamado "Escritura de Constitución del Grupo" (en inglés, Articles of Grouping) que especifica sus objetivos, afiliación y estructuras de gobierno corporativo. De este modo, el análisis de los grupos de negocios en China no está sujeto a la crítica presentada por una de las corrientes de comentarios sobre el gobierno corporativo japonés, el que expone que el concepto de keiretsu es una "fábula" creada a través de una búsqueda de datos llevada a cabo ideológicamente. Véase en general Miwa y Ramseyer (2006). Cualquiera sea el caso sobre el argumento de la "fábula" en Japón (para una refutación, véase Milhaupt (2002) p. 425), los grupos empresariales en China claramente existen a los ojos del Estado. Véase citas 44 y 56. 
en un proceso de dotación de personal en rotaciones, dirigido conjuntamente por el partido comunista y SASAC.

Los aspectos jerárquicos de la organización industrial china se advierten de inmediato: ellos van desde la integración vertical de las empresas a lo largo de la cadena de producción hasta el carácter jerarquizado, desde arriba hacia abajo, en la formulación y transmisión de la política industrial en un régimen político autoritario ${ }^{34}$. Pero el sistema chino no es simplemente uno en el que grupos verticalmente integrados transmiten órdenes desde los planificadores estatales centrales a SASAC y de ahí hacia abajo a través de una cadena de empresas verticalmente integradas. Estas estructuras jerárquicas están incrustadas en densas redes - no solo de otras empresas, sino que también del partido comunista y órganos gubernamentales. Estas redes parecen facilitar el flujo de información tanto desde abajo hacia arriba como desde arriba hacia abajo. Ellas fomentan el intercambio de relaciones y la colaboración en muchos niveles de producción y en los procesos de implementación de políticas públicas. Y ellas entregan potentes incentivos a los líderes dentro del sistema porque el éxito en los negocios lleva a promociones y recompensas en el ámbito político, y viceversa. Esta combinación de jerarquía autoritaria y colaboración dentro de potentes estructuras de incentivos nos hace recordar otro mecanismo capitalista de transiciones- las inversiones en capital de riesgo ${ }^{35}$.

Como señalaremos más adelante en detalle, estas densas redes son el resultado de numerosas sendas que unen los componentes individuales del sistema. Algunas son creadas a través de medios legales formales, tales como un contrato o mediante relaciones accionarias. Otras son el resultado de prácticas del personal seguidas por el partido comunista y SASAC. Incluso otras son incorporadas en la peculiar noción de "representación" en los órganos gubernamentales chinos, que asigna determinados cargos a selectos hombres de negocios. Hemos llamado a esta característica del sistema puentes institucionales.

Una manera útil de ver estas redes construidas al centro del capitalismo de estado chino es a través del concepto "coalición englobante total"36 de Mancur Olson. Para él, este es un grupo que representa un segmento suficientemente grande de la población que tiene los incentivos para que crezca la economía en general, opuesto a "coalición distributiva” que representa a un segmento más pequeño de la sociedad, que trata de conseguir un pedazo más grande para sus miembros ${ }^{37}$. Olson se enfocó en el tamaño de los grupos

\footnotetext{
34 La estructura de una autoridad vertical en las SOEs chinas es un reflejo de la estructura jerárquica gubernamental (llamada xitong, o "sistema") para la administración económica, desde donde ellas fueron creadas. El xitong es "un grupo de entes burocráticos estatales que se dedican en conjunto a una amplia tarea que le han encargado las altas autoridades políticas.” LieberThal (2004) p. 218. Las SOEs chinas fueron creadas gracias a los esfuerzos que buscaban "reestructurar... las relaciones de manera que el gobierno y el Partido Comunista no administren directamente la mayoría de las empresas y organizaciones sociales (tales como los centros de investigación). El gobierno [intentó] focalizarse en proveer un marco regulatorio y de amplias políticas públicas más que un detallado control administrativo. ... El partido comunista, sin embargo, [planificó] reteniendo el derecho de nombrar a los líderes de esas unidades, incluso cuando ya no eran objeto de una conducción administrativa gubernamental".

35 Gilson y Milhaupt (2011) p. 233.

36 Olson (1982) cita 13, p. 48

37 Olson (1982) pp. 44-48. Olson nos entrega un típico grupo especial de interés representando un acotado
} 
como la clave para distinguir entre coaliciones englobantes y distributivas, pero pareciera ser importante que una coalición englobante incluye a todos los potenciales miembros cuya participación tenga un impacto importante en el desarrollo, una amplia variedad de élites políticas y empresariales en la sociedad. La jerarquía interconectada, que comprende tanto a la alta gerencia de los grupos empresariales como a los altos miembros del partido comunista y funcionarios públicos, es una manera de crear precisamente este tipo de gran coalición de élites con control sobre la formulación e implementación de políticas públicas de desarrollo.

Nuestro propósito de introducir estos conceptos es descriptivo, no normativo. No afirmamos que estas características de la organización industrial china necesariamente conduzcan a la eficiencia en la producción. Olson señalaba que las organizaciones englobantes no conducen necesariamente bajo toda circunstancia a la eficiencia ${ }^{38}$. Lo más probable es que las redes que describimos producen efectos contrarios: ellas mejoran la eficiencia al fomentar compartir información, reduciendo el oportunismo en la repetición de acciones, entregando potentes incentivos y reduciendo fricciones en la implementación de las políticas públicas. Pero ellas también reducen la competencia y la transparencia, multiplicando las relaciones de agencia y mitigando las restricciones presupuestarias ${ }^{39}$. La pregunta interesante para nosotros no es si el sector estatal es más eficiente que el sector privado, sino cómo el sector estatal ha sostenido el crecimiento económico y producido empresas globalmente importantes en ausencia de la infraestructura formal que se supone esencial en las teorías corrientes sobre las relaciones entre instituciones y desarrollo.

\section{Un modelo estilizado}

A continuación, hacemos uso de los conceptos de jerarquía interconectada y puentes institucionales para enfocar las principales características organizativas, y sus conexiones, de las estructuras del grupo empresarial en las que están alojadas las grandes empresas estatales.

Se destacan cuatro características de esta estructura, que serán el foco de nuestra atención en el resto de este artículo. Primero, en contraste con los principales keiretsu japoneses de posguerra y con los chaebol coreanos ${ }^{40}$, los grupos empresariales chinos se

segmento de la sociedad como ejemplo de coalición distributiva; una organización que efectúa lobby que incluye todas las más importantes empresas en un país industrializado es un ejemplo de coalición englobante. Véase Olson (1982) pp. 41-48.

38 Olson (1982) p. 48.

39 Concordante con esta conclusión, los estudios nos entregan relatos contradictorios sobre la eficiencia del sector público chino. Véase, por ejemplo, Allen y Shen (2013) ("los estudios realizados... no son concluyentes....”). Para una visión positiva del desarrollo de las SOEs en la última década, véase Gabrielle (2010) p. 325. Al menos según los datos entregados por SASAC, las grandes SOEs nacionales son más rentables que las grandes empresas privadas. Véase SASAC (2010a) pp. 196-197 (mostrando utilidades totales en 2009 de 815 mil millones de yuanes chinos en las 133 grandes empresas estatales, contra 218 mil millones de yuanes chinos para las 500 empresas privadas más grandes, por ingresos); SASAC (2010b) véase cita 15 p. 89. Desde luego, el acceso a un financiamiento de bajo costo y otros subsidios estatales, como también beneficios monopólicos, puede ayudar a explicar la rentabilidad más alta del sector estatal. Para una evaluación bastante crítica de las SOEs en el proceso de reforma económico chino, véase Unirule Institute Of Economics (2011).

40 Típicamente, los keiretsu son grupos diversificados de empresas organizadas alrededor de un "banco principal" el que provee créditos y tiene acciones de las sociedades miembros del grupo (por ejemplo, el grupo Mit- 
componen de sociedades verticalmente integradas enfocadas en una industria o sector particular, y no de grupos diversificados involucrados en una amplia gama de industrias. Y de una manera complementaria, y nuevamente en contraste con las estructuras del keiretsu o del chaebol, el accionariado es jerárquico: las empresas más altas en la estructura tienen la propiedad de las subsidiarias, pero hay muy poca participación accionaria de empresas más bajas en las más altas o propiedad accionaria cruzada. Segundo, casi todos los grupos empresariales chinos poseen cuatro componentes principales: (1) la sociedad principal holding (matriz), cuyas acciones son totalmente de propiedad de SASAC; (2) una o más subsidiarias que cotizan en bolsa -la cara global del grupo empresarial- en las que la mayoría de sus acciones pertenecen a la sociedad matriz; (3) una sociedad financiera, que sirve para variadas necesidades de financiamiento del grupo, y que tiene ciertos paralelos con los bancos principales japoneses ${ }^{41}$; y (4) un instituto de investigación que coordina los procesos de innovación del grupo. Tercero, la supervisión se lleva a cabo a través de dos estructuras paralelas: una basada en el derecho corporativo, con SASAC como el accionista controlador, y una segunda, basada en la estructura del partido comunista que sigue de cerca a la jerarquía corporativa, especialmente en lo relativo a la designación de los altos ejecutivos.

Crucialmente, sin embargo, estos componentes del grupo, como sus altos ejecutivos, están muy interconectados al sistema más amplio de la organización industrial. Aunque los distintos grupos empresariales son legal y funcionalmente diferentes unos de otros, los grupos complementarios están vinculados de manera importante. Los joint ventures intergrupales, alianzas estratégicas y la adquisición de acciones son los mecanismos corporativos que permiten realizar dichas conexiones. El Estado-partido, actuando a través de SASAC y del Departamento de Organización del Partido, nos entrega otro medio, probablemente más importante, para unir los grupos en un todo complementario ${ }^{42}$. Finalmente, los aspectos económicos de esta estructura están comunicados a través de canales institucionalizados de personal y prácticas políticas con órganos de gobierno, tales como el Congreso Nacional del Pueblo, órganos importantes del partido comunista e instituciones estatales no económicas como las universidades ${ }^{43}$. Estos son los puentes institucionales que unen los componentes separados del sistema.

\section{OrÍGEnes de los grupos empresariales CHinos}

Hemos visto que la agrupación es la característica organizativa predominante de las SOEs chinas. Mientras, como se explica más adelante, el contorno actual del sistema es un producto de dos décadas de experimentación, la decisión de organizar las empresas en grupos fue parte de la estrategia de reforma económica inicial, basada en la observación del

\footnotetext{
subishi). Los chaebol coreanos son grupos grandes y diversificados de empresas que se centran en el empresario fundador o sus descendientes (por ejemplo, Samsung), con una amplia propiedad accionaria cruzada y otras formas de colaboración entre sus miembros. Para conocer más de estos grupos, véase, por ejemplo, Milhaupt (1998) p. 1145, 1161-1165.

${ }^{41}$ En China, la idoneidad para constituir una sociedad financiera es uno de los beneficios más importantes de registrarse como un grupo empresarial.

${ }_{42}$ Véase Parte III.

43 Véase Parte II.C.3.
} 
desarrollo económico en otros lugares. Como una investigadora lo ha hecho notar, "uno de los esfuerzos más profundos de China para lograr un crecimiento industrial ha sido la formación de los grupos empresariales. La separación deliberada de las antiguas empresas estatales de la dirección de las oficinas gubernamentales es, en parte, el resultado de la percepción que los grupos empresariales, con unas específicas características estructurales, protegen a las empresas en otros países de los impactos y desafíos del progreso" ${ }^{44}$.

El fomento gubernamental para la formación de grupos empresariales, y de esta manera promover el crecimiento de grandes empresas estatales, es una estrategia común. En el siglo XX, los grupos empresariales sirvieron como motores del desarrollo en muchos países, que han llevado a cabo estrategias económicas muy diferentes, incluyendo a Corea del Sur bajo Park Chung Hee, Chile bajo Augusto Pinochet y Japón bajo los oligarcas del período Meiji ${ }^{45}$. En muchos aspectos, el uso por parte de China de los grupos empresariales refleja los mismos móviles para la formación de grupos que se ven en otras zonas del mundo, tales como, llenar vacíos institucionales en lugares donde el estado de derecho es débil, incorporar mercados de capitales, reunir recursos escasos y reducir los costos transaccionales en la administración de la política económica ${ }^{46}$.

Los grupos empresariales alrededor del mundo se han originado, por regla general, en empresas familiares. Los lazos de parentesco, las redes de prestigio y la repetición de transacciones crean un ambiente propicio a la actividad comercial en ausencia de instituciones formales. También, los empresarios exitosos pueden haber sido cuidadosamente seleccionados por los líderes políticos para trabajar con el Estado, y pueden haber recibido distintos beneficios estatales para promover el crecimiento del grupo y su diversificación. De esta manera, en el patrón típico, los grupos empresariales se forman a partir de una empresa familiar en respuesta tanto a debilidades institucionales (por ejemplo, ausencia de tribunales que funcionen adecuadamente para hacer cumplir los contratos entre los socios comerciales) como a política gubernamental (por ejemplo, préstamos a tasas de interés preferencial para grandes inversiones en la industria pesada $)^{47}$.

En la época postreforma en China, el camino fue un poco diferente. Cuando este país se alejó de la planificación centralizada, no había empresarios privados en la economía, la que estaba repleta de elementos redundantes en su capacidad productiva debido a políticas económicas autárquicas, además de estar muy fragmentada por líneas burocráticas. Los planificadores económicos chinos tenían interés en los grupos empresariales japoneses

\footnotetext{
44 Keister (1998) p. 436.

45 Véase Gilson y Milhaupt (2011), pp. 243-257, para más información sobre el rol de los grupos empresariales en el desarrollo económico de Corea del Sur y Chile, Morck y Nakamura (2007) p. 543, para más información sobre el rol de los grupos empresariales antes de 1945 en Japón.

46 Documento No 71 de 1991 del Consejo de Estado de China sobre Guanyu Xuanze Yipi Daxing Qiye Jituan Jinxing Shidian de Qingshi [Instrucciones sobre la Selección de un Grupo de Grandes Grupos Empresariales para Experimentación]; Opiniones del 16 de diciembre de 1987, de la Comisión de Reforma del Sistema Económico Nacional y la Comisión Nacional Económica ambas del Consejo de Estado de China, sobre Guanyu Zujian he Fazhan Qiye Jituan de Jidian Yijian [Varias opiniones sobre la Construcción y Desarrollo de los Grupos Empresariales].

47 Véase Gilson (2007) pp. 633, 645.
} 
y coreanos como modelo para promover el desarrollo económico ${ }^{48}$, pero no había ningún plan rector para replicarlos en su país. Los grupos empresariales que existen hoy no surgieron completamente delineados de la mente de los planificadores económicos chinos; más bien son el resultado de un largo proceso de experimentación con colaborativas formas de producción.

Al principio, el trabajo más urgente fue integrar estructuras económicas inconexas y mejorar la asignación de recursos. A principios de los años 80, el gobierno chino lanzó una serie de iniciativas regionales y de nivel empresarial para promover estas reformas. Una de tales iniciativas fue la introducción de las alianzas de negocios (jingji lianying) como un mecanismo de integración a nivel empresarial. Estas alianzas, constituidas normalmente mediante un contrato, fueron diseñadas para alentar la colaboración de las SOEs de varias jurisdicciones, a través de distintos sectores industriales, y entre las SOEs y otras organizaciones, como los centros de investigación y universidades. La colaboración dentro de una alianza de negocios podía tomar variadas formas, tales como relaciones estabilizadoras de oferta y demanda, o compartir marketing e instalaciones de producción ${ }^{49}$. Se utilizaron principalmente en el período 1980-1986, formándose alrededor de 32.000 alianzas de negocios entre 63.000 $\mathrm{SOEs}^{50}$.

La idea de la alianza de negocios, sin embargo, fue ineficaz en promover la reforma económica. Las alianzas padecían una falta de dirección unificada y crearon un atasco regulatorio al incrementar exponencialmente el número de organismos gubernamentales con jurisdicción sobre los emprendimientos económicos ${ }^{51}$. Con el tiempo, los planificadores se mostraron insatisfechos con la colaboración en base solo a un contrato, cambiando de estrategia en la segunda mitad de los años 80. Aunque las alianzas cayeron en desgracia, estas primeras formas de colaboración crearon redes empresariales y mecanismos de gobierno corporativo que se convirtieron en pilares para la construcción de los grupos empresariales en los próximos años.

En la próxima fase, los planificadores económicos confiaron más en formas perdurables y englobantes de colaboración entre empresas. En vez de contratos, las empresas se comenzaron a vincular mediante estructuras organizativas basadas en la propiedad accionaria. Las SOEs fueron organizadas en grupos para profundizar la especialización, promover

\footnotetext{
48 En 1979, un grupo de especialistas chinos viajó varias veces a Japón para entender la organización y operación de los keiretsu, informando de sus resultados al Consejo de Estado. Véase Hu y Zang (2005); ver también Keister (1998) pp. 405-406. Un funcionario gubernamental que trabajó en un ministerio económico bajo Deng enfatizó la atracción del líder chino por la organización industrial y las estructuras regulatorias económicas de Japón. Entrevista a un ex funcionariom SASAC, Pekín (20 de junio de 2011).

49 Las regulaciones promulgadas por el Consejo de Estado en 1980 entregaban el marco para tales alianzas. Dichas regulaciones especificaban que las alianzas deberían constituirse mediante un contrato, con disposiciones que señalasen el ámbito de colaboración y reparto de utilidades y pérdidas. Además, las regulaciones requerían la formación de un comité compuesto por miembros de la alianza para administrarla.

50 Consejo de Estado de China (1987); Informe de Trabajo del Gobierno, del Consejo de Estado, de 1987, hecho público en la 5ta Reunión del 6to Congreso Nacional del Pueblo, 25 de marzo de 1987; Wu (2003) p. 102.

51 Por ejemplo, una alianza de negocios entre dos empresas en diferentes industrias y localizadas en distintas regiones resultaría en una supervisión de cuatro organismos gubernamentales - dos reguladores industriales y dos gobiernos locales.
} 
economías de escala, ganar competitividad en los mercados domésticos e internacionales y separar las actividades comerciales (de las SOEs) del rol regulatorio del gobierno. En 1987 el gobierno central entregó una definición legal de "grupo empresarial" (qiye jituan) y especificó los requerimientos organizacionales para registrarse como tal ${ }^{52}$. La introducción de un concepto formal de grupo empresarial por las autoridades del gobierno central generó un gran interés en la formación de grupos a nivel local. Sin embargo, con frecuencia estos grupos no eran más que unidades administrativas del gobierno local transformadas apresuradamente, sin coherencia económica ni mecanismos de gobierno corporativo.

Tratando de resolver esos problemas, en los años 90 el gobierno central chino tomó más control en la creación de los grupos. El Consejo de Estado creó 57 grupos empresariales experimentales en 1991, y agregó 63 grupos adicionales en 1997. Estos 120 grupos experimentales se concentraban en industrias claves, tales como la automotriz, maquinaria, electrónica, acero y transportes. Los grupos se beneficiaron con una amplia gama de políticas preferenciales en áreas que van desde los tributos a los contratos con el gobierno y la idoneidad para cotizar en bolsa. El propósito para establecer estos grupos según el gobierno fue el conseguir economías de escala, facilitar la colaboración entre las empresas y mejorar la competitividad internacional. Además, la formación de grupos verticalmente integrados tenía la ventaja administrativa de hacer más eficiente el control sobre la economía: un pequeño número de grandes empresas serviría de conducto a través del cual la política económica se transmitiría a un enorme número de sociedades organizadas bajo las empresas centrales. Hacia mediados de los años 90, la creación de grandes empresas estatales era una meta explícitamente reconocida por el gobierno central ${ }^{53}$.

Después de años de experimentación con estructuras organizativas, en 1998 se hizo público un concepto relativamente claro de grupo empresarial con la promulgación de las Reglas Provisionales sobre el Registro de los Grupos Empresariales ${ }^{54}$. Aunque se trata de normas "provisionales", estas todavía continúan vigentes. Sujeto a varios requisitos de en$\operatorname{trada}^{55}$, un grupo empresarial se define como un grupo de entidades compuesto de cuatro estratos: (1) una sociedad matriz y (2) sus subsidiarias controladas (los dos estratos obligatorios), junto a dos estratos opcionales (3) subsidiarias no controladas y (4) otras empresas que colaboran con la sociedad matriz o sus subsidiarias. Para registrarse, los miembros del

52 Documento No 71 de 1991 del Consejo de Estado de China sobre Guanyu Xuanze Yipi Daxing Qiye Jituan Jinxing Shidian de Qingshi [Instrucciones sobre la Selección de un Grupo de Grandes Grupos Empresariales para Experimentación]; Opiniones del 16 de diciembre de 1987, de la Comisión de Reforma del Sistema Económico Nacional y la Comisión Nacional Económica ambas del Consejo de Estado de China, sobre Guanyu Zujian he Fazhan Qiye Jituan de Jidian Yijian [Varias opiniones sobre la Construcción y Desarrollo de los Grupos Empresariales].

53 Congreso Nacional del Pueblo (1996).

54 Documento No 15 de 1997 del Consejo de Estado de China sobre Qiye Jituan Dengji Guanli Zhanxing Guiding [Reglas Provisionales sobre el Registro de los Grupos Empresariales].

55 Para formar un grupo, la sociedad matriz debe tener un capital registrado de al menos 50 millones de yuanes chinos (alrededor de US\$8 millones a marzo del 2013) y al menos cinco subsidiarias. El capital total registrado de la matriz y sus subsidiarias debe ser de al menos 100 millones de yuanes chinos (US\$16 millones). Art. 5 del Documento No 15 de 1997 del Consejo de Estado de China sobre Qiye Jituan Dengji Guanli Zhanxing Guiding [Reglas Provisionales sobre el Registro de los Grupos Empresariales]. 
grupo deben firmar un acuerdo (bajo la forma de Escritura de Constitución del Grupo), especificando sus límites y reglas de gobierno corporativo ${ }^{56}$. Solo los grupos empresariales están habilitados para obtener importantes beneficios, como la idoneidad para constituir una sociedad financiera ${ }^{57}$.

El proceso de formación del grupo, junto con el paso más elemental de "societización" de las empresas estatales -o sea, la transformación en sociedades anónimas de los organismos estatales involucrados en actividades comerciales- planteó un controvertido problema de agencia: cuando un activo de la sociedad es teóricamente de propiedad del "pueblo" ¿quién es el mandante? Captando este problema, se realizaron varios intentos para crear un accionista controlador, lo que llevó finalmente al establecimiento de SASAC en $2003^{58}$. En teoría, SASAC representa al Estado como "propietario" y ejercita los derechos del accionista en su nombre. El rol característico de SASAC, como accionista controlador dentro del contexto del Estado-partido, será analizado en la Parte III de este artículo.

\section{LOS GRUPOS EMPRESARIALES NACIONALES}

En esta parte utilizaremos los conceptos de jerarquía interconectada y puente institucional para examinar con algún detalle los miembros más importantes, la estructura interconectada y los mecanismos de gobierno corporativo interno (Partes II. A-C) y entregar dos ejemplos para ilustrar las variantes de los grupos empresariales en China (Parte II. D).

\section{A. Componentes}

\section{Sociedad matriz (central)}

Como se ha señalado, los grupos empresariales chinos tienen una estructura jerárquica con varios estratos. A la cabeza del grupo está la sociedad matriz. Por regla general, las sociedades matrices fueron formadas mediante la "societización" de algún ministerio gubernamental con jurisdicción sobre determinada industria. Por ejemplo, cada sociedad matriz de los grupos petroleros nacionales fue escindida del antiguo ministerio del petróleo y transformada en una sociedad anónima. La sociedad matriz actúa como una sociedad holding, sirviendo de intermediaria entre SASAC y las empresas del grupo que se dedican a la producción propiamente tal. La sociedad matriz coordina el flujo de información y la asignación de recursos dentro del grupo. Transmite la política de empresa hacia abajo desde el Estado a los miembros del grupo, y provee de información y consejos hacia arriba, desde el grupo hacia los planificadores económicos y gubernamentales. Como unos investigadores chinos explican,

"Los sectores clave y las industrias más importantes son todavía controlados por el Estado a través de empresas de su total propiedad o a través de aquellas en las que tiene alguna participación en el capital... En realidad, el Estado puede controlar las industrias

\footnotetext{
56 Medidas Administrativas sobre Sociedades Financieras en Grupos Empresariales (2006) Art. 1.

57 Parte II. A. 3.

58 Parte III. A.
} 
importantes y las áreas más significativas de la economía simplemente teniendo a su alcance algunos cientos de grandes sociedades holding estatales o grupos empresariales" 59 .

\section{Sociedad cotizada en bolsa}

La cara externa del grupo empresarial no es el conjunto de sociedades sino una sola empresa, cuyas acciones se transan públicamente en la bolsas de China, Hong Kong y también, frecuentemente, en otras bolsas importantes del mundo. Por ejemplo, PetroChina, una de las empresas petroleras más grandes del mundo, cuyas acciones se transan en las bolsas de Shanghai y de Nueva York, es la cara externa del Grupo CNPC, cuya sociedad matriz es la China National Petroleum Corporation. La estrategia de SASAC, al administrar los grupos bajo su supervisión, ha sido la de consolidar activos de alta calidad en compañías específicas y procurar que dichas empresas coticen en bolsa. Estas sociedades cotizadas en bolsa son el foco de la mayoría de los estudios sobre gobierno corporativo chino.

\section{Sociedad financiera}

Uno de los beneficios más importantes de registrarse como grupo empresarial es la idoneidad para constituir una sociedad financiera, una institución financiera no bancaria que provee servicios a los miembros del grupo ${ }^{60}$. Las sociedades financieras están exentas de la prohibición general de préstamos entre empresas ${ }^{61}$. Bajo el actual marco legal, la sociedad financiera proporciona servicios a los miembros del grupo similares a los entregados por los bancos comerciales o bancos de inversión. Sujeto a la aprobación de los reguladores bancarios, las sociedades financieras están autorizadas para realizar una amplia gama de actividades, incluyendo aceptar depósitos y dar préstamos a empresas del grupo, servicios de pago, seguros y entrega de divisas a los miembros y suscribir los valores de comercio de las sociedades. Ellas también ofrecen préstamos de consumo relacionados con los productos de los miembros del grupo e invierten en valores emitidos por instituciones financieras ${ }^{62}$. Su principal fuente de financiamiento son los depósitos de las sociedades del grupo. Casi todas las sociedades financieras pertenecen a grupos estatales, de nivel nacional o provincial $^{63}, y$ muchas de ellas son de gran tamaño.

La sociedad financiera china, en su rol de centro neurálgico de las transacciones financieras del grupo, se parece al banco principal japonés, al menos a como operaba en los buenos tiempos de las finanzas y gobierno corporativo del Japón de posguerra. Sin embar-

\footnotetext{
59 Zheng et al. (2009) p. 2.
}

60 Véase Art. 2 de las Medidas Administrativas para las Sociedades Financieras de los Grupos Empresariales. La autorización no es automática. Además de varios requisitos de entrada de capital y rentabilidad, los reguladores bancarios exigen que las funciones comerciales del grupo estén de acuerdo con las políticas industriales del gobierno. Art. 7, ítem 1 de las Medidas Administrativas para las Sociedades Financieras de los Grupos Empresariales.

61 Art. 61 de las Reglas Generales sobre Préstamos (1996).

62 Arts. 28 y 29 de las Medidas Administrativas para las Sociedades Financieras de los Grupos Empresariales (2006).

$63 \mathrm{Al}$ año 2009, eran nueve las sociedades financieras de propiedad privada o colectiva y cuatro las que estaban bajo propiedad extranjera, las últimas sirviendo a grupos empresariales alemanes y japoneses. Seis sociedades financieras de propiedad extranjera que operaban independientemente de grupos empresariales fueron obligadas a cerrar o a transformarse en bancos en el año 2000. Véase SASAC (2010c) p. 284. 
go, existen varias diferencias importantes que hay que señalar. En contraste con la amplia participación societaria cruzada (aunque en un bajo nivel) entre el banco principal japonés y sus prestatarios más importantes ${ }^{64}$, la sociedad financiera china casi no posee acciones de otras empresas del grupo, y pocas o ninguna otra empresa a excepción de la sociedad matriz tiene acciones en la sociedad financiera. Aunque la sociedad matriz podría utilizar la sociedad financiera como una ayuda para supervisar a los miembros del grupo, no hay evidencia que aquella realice una función de monitoreo, particularmente en relación con la sociedad matriz o las empresas del grupo que cotizan en bolsa ${ }^{65}$.

El sistema bancario japonés, en especial sus supuestas ventajas en el gobierno corporativo, fue atractivo para los observadores chinos durante el período formativo del proceso transicional económico de China a principios de los años 90, particularmente por los beneficios de gobierno corporativo percibidos ${ }^{66}$. En este período la mayoría de los juristas y economistas sostenía que la propiedad accionaria en sus prestatarios por parte del banco principal tenía importantes beneficios de gobierno corporativo ${ }^{67}$ y que el banco principal servía de observador "delegado" o "contingente" a favor de otros prestamistas de las empresas del grupo ${ }^{68}$. Se sostenía incluso que el banco principal sustituía al mercado en el control corporativo japonés al reemplazar a los gerentes de aquellas empresas que estuviesen con problemas financieros ${ }^{69}$. A pesar de lo anterior, las sociedades financieras chinas se parecen muy poco al sistema del banco principal japonés, sirviendo primariamente como instrumento de la sociedad matriz en la asignación de capital dentro del grupo. Además, a diferencia de la situación japonesa, el sector corporativo chino tradicionalmente casi no posee acciones en el sector bancario.

Dada la atracción china por el modelo japonés durante el período formativo inicial de los grupos empresariales, ¿por qué no buscaron los planificadores una estructura financiera y de gobierno corporativo que guardara un parecido más cercano al sistema japonés de fines de los años 80 ? Se pueden dar dos explicaciones complementarias, muy vinculadas al sistema general de gobierno económico chino. Primero, la dispersión de derechos de administración en las empresas miembros hacia instituciones financieras no bancarias podría haber diluido y complicado la estructura jerárquica del manejo económico, hecho posible por la formación de grupos bajo una supervisión estatal centralizada. Segundo, la creación de sociedades financieras no bancarias dentro de los grupos empresariales -como un comentarista ha dicho "fuera del plan de los intermediarios financieros" 70 - plantea una obvia amenaza competitiva al sector (en su mayor parte estatal) bancario comercial. Por lo tanto,

\footnotetext{
64 Cita 38.

${ }_{65}$ Qian (1994) pp. 552, 585-586. Por ejemplo, la sociedad financiera puede rechazar el envío de fondos fuera del grupo sin la aprobación de la sociedad matriz, y puede informarle sobre las transacciones financieras de las compañías miembros del grupo.

66 QIAN (1994) pp. 577, 585 (“Los parecidos históricos sugieren que China puede beneficiarse más tomando características del modelo financiero japonés que las de otros modelos financieros para lograr el objetivo de reestructurar su sector corporativo mientras estabiliza su economía”).

${ }^{67}$ Sheard (1989) p. 403; Qian (1994) pp. 585-586.

68 AOKI et al. (1994) p. 1.

69 Sheard (1989) p. 400.

${ }^{70}$ QIAN (1994) p. 569.
} 
los reguladores chinos han estado pendientes de no expandir el ámbito de actividades de las sociedades financieras al punto que puedan constituir un completo sustituto de los bancos comerciales chinos.

\section{Centros de investigación}

Los planificadores chinos han estimulado a los grupos empresariales para que incorporen como miembros a centros de investigación, y de esta manera se promueva el desarrollo de la alta tecnología incrementándose la competitividad internacional ${ }^{71}$. Casi todos los grupos empresariales de rango nacional tienen uno o más centros de investigación, los que realizan I+D (investigación + desarrollo), particularmente en áreas relacionadas con investigación aplicada a los productos y procesos de producción del grupo. Frecuentemente, los centros de investigación empresarial colaboran con las universidades en proyectos determinados para obtener complementariedades entre el enfoque aplicado en los programas empresariales I+D y el planteamiento teorético de los investigadores universitarios.

Constituidos típicamente como instituciones sin fines de lucro, los centros de investigación reciben financiamiento de la sociedad matriz del grupo. Varios centros de investigación en aquellos grupos empresariales con una amplia gama de productos pueden estar en distintos niveles de jerarquía, con un centro de investigación principal afiliado con la sociedad matriz y los centros de estudios secundarios establecidos bajo determinadas subsidiarias operativas. La propiedad intelectual generada en las actividades de investigación pertenece por regla general a la sociedad matriz, o es asignada por contrato en proyectos conjuntos con centros que no pertenecen al grupo.

\section{B. Afiliación y gobierno interno}

La afiliación en la mayoría de los grupos empresariales está basada en la propiedad accionaria sobre las compañías pertenecientes al grupo por parte de la sociedad matriz. Aunque bajo las regulaciones de los grupos empresariales está permitida la afiliación basada puramente en relaciones contractuales entre las empresas, ello no es común ${ }^{72}$. El predominio de los lazos accionarios es un reflejo del interés tanto de la sociedad matriz como del Estado. Para la sociedad matriz, la propiedad accionaria provee una forma de control más directa y flexible que la contractual. Para el Estado, los objetivos de la formación del grupo se potencian más efectivamente a través de la propiedad accionaria que a través de afiliaciones sueltas -en efecto, el concepto original de alianza económica fue abandonado en favor del concepto de grupos empresariales precisamente por esta razón ${ }^{73}-$.

En considerable contraste con los grupos empresariales japoneses y coreanos, la propiedad accionaria en los grupos empresariales chinos se dirige normalmente solo en una dirección: desde la sociedad matriz hacia las subsidiarias. La propiedad accionaria cruzada en los grupos empresariales chinos es casi inexistente. Con el predominio de las relaciones equi-

\footnotetext{
71 Documento No 8 de 1987.

72 En el año 2000, el 87\% de los grupos empresariales incluían miembros relacionados no puramente contractuales. Hahn y Lee (2006) pp. 207, 226.

73 Cita 49.
} 
tativas por sobre aquellas puramente contractuales, las preocupaciones del gobierno -ambas, corporativas y políticas- parecen ser la razón principal de la estructura jerarquizada de dominio. A la sociedad matriz -al ser la sociedad dominante del grupo, con decisión final sobre los recursos humanos y asuntos estratégicos- prácticamente no le es útil que exista propiedad accionaria desde abajo hacia arriba. Para el gobierno, el rol de la sociedad matriz como supervisora y administradora delegada de las empresas del grupo no se vería mejorada -más bien se complicaría - si existiesen vínculos de propiedad accionaria cruzada entre las empresas del grupo. Además, sabiendo que en países como Japón la propiedad accionaria cruzada se usa para promover la mejora de la supervisión de los miembros del grupo, esta función podría no ser una alternativa en las estructuras de los grupos empresariales chinos dada la participación omnipresente del Partido Comunista en las empresas y otras formas de supervisión del Estado-Partido fuera de los límites de las normas de Derecho Corporativo ${ }^{74}$.

Las estructuras internas del gobierno del grupo se especifican en un documento jurídicamente vinculante llamado Escritura de Constitución del Grupo, del que son parte todos sus miembros. Este documento es un formulario de contrato estándar entregado por el Estado, obligatorio para todos los grupos empresariales registrados, y su contenido específico está compuesto en su gran mayoría por disposiciones preestablecidas. En la práctica, la sociedad matriz dicta los términos de la Escritura de Constitución del Grupo, y las normas de gobierno corporativo interno le entregan tanto derechos de veto como derechos más amplios de gobierno con respecto al grupo. Hay muchos casos en los que la Escritura de Constitución del Grupo provee estructuras plenarias o de administración para facilitar la toma de decisiones grupales o delegadas, respectivamente, pero por lo general estos órganos solo tienen una calidad consultiva o están estructurados de tal manera que la sociedad matriz efectivamente controla los procesos de toma de decisión. En pocas palabras, el gobierno corporativo en un grupo empresarial chino es en buena parte un proceso que va desde arriba hacia abajo, pero que está abierto a la información y participación desde abajo hacia arriba.

\section{Redes}

Anteriormente hemos señalado los componentes principales de los grupos empresariales chinos y los mecanismos a través de los cuales se vinculan sus miembros. Pero el funcionamiento del capitalismo estatal chino opera uniendo grupos empresariales, formando redes más densas de organizaciones afiliadas al Estado-partido. Estas redes afiliadas al Estado generan las principales características del capitalismo de Estado chino y produce las mayores dificultades para los competidores extranjeros y reguladores. Ahora veremos las redes más densas en las que dichos grupos están integrados.

\section{Redes intergrupales}

A pesar de que los grupos en la misma industria puedan competir en el mercado doméstico, para proyectos en el extranjero, SASAC estimula la colaboración entre los grupos nacionales para así incrementar su competitividad global. Estos vínculos, frecuentemente entre grupos en industrias complementarias, están estructurados para facilitar el desarrollo

74 Citas 88 y 101. 
tecnológico y otros objetivos, tales como el compartir información, marketing y el reunir un fondo común para proyectos que precisen una gran inversión de capital. Estos vínculos toman normalmente dos formas: empresas conjuntas de carácter accionarial (equity joint ventures) y alianzas contractuales.

En la mayoría de las economías, estas formas de colaboración producirían claros conflictos contra la libre competencia. China promulgó su Ley Antimonopolios en 2008, la que debería revisar este tipo de alianzas (junto con las fusiones y otras combinaciones entre las SOEs $)^{75}$. Sin embargo, en la práctica, no se aplica la Ley Antimonopolios a las empresas nacionales que funcionan bajo $\mathrm{SASAC}^{76}$.

\section{Redes intergrupales central-locales}

En determinados casos los grupos nacionales que funcionan bajo SASAC están vinculados a grupos empresariales controlados por los gobiernos locales. Estos nexos son el resultado de una dinámica que se ha desarrollado entre el gobierno central y los gobiernos locales. Inicialmente, los gobiernos locales buscaban inversión en los grupos con presencia nacional para poder rescatar a las SOEs locales que estaban en un estado agónico. A medida que se expandían los grupos nacionales, los gobiernos locales empezaron a verlos como una amenaza competitiva. El proteccionismo local aumentó y se impulsó la creación de “importantes grupos empresariales provinciales". La relación entre los grupos empresariales con presencia nacional y local pareciese estar en cambio nuevamente debido a la crisis financiera global, lo que ha provocado una cooperación renovada entre ellos. Los gobiernos locales ven ahora a las grandes empresas estatales como fuente de ayuda para las pequeñas y medianas empresas, las que se han visto afectadas por la pérdida de apoyo de las empresas extranjeras y privadas ${ }^{77}$. Los grupos nacionales están presionados, por los supervisores gubernamentales, a crecer. Por eso, la vinculación con los grupos locales es un camino abierto para la expansión.

\section{Redes entre los grupos empresariales y el Estado-partido}

Al ser las SOEs supervisadas por SASAC, todas las grandes empresas estatales están conectadas al gobierno central. Pero este simple silogismo esconde la densidad de redes que

75 Ley antimonopolio de la República Popular China.

76 Véase, por ejemplo, ZHeNG (2009). La única excepción hasta la fecha es una investigación antimonopolios sobre el abuso de dominio de mercado de la banda ancha doméstica por China Telecom y China Unicom. A pesar del tamaño de las SOEs y su activo rol en fusiones y adquisiciones, prácticamente no hay a la fecha resoluciones que digan relación con SOEs. TAN (2012). China tiene tres organismos distintos para hacer efectiva la legislación antimonopolios: el Ministerio de Comercio, responsable del examen de fusiones, la Comisión Nacional de Desarrollo y Reforma, responsable de acuerdos restrictivos y abuso de posición dominante en cuanto a precios, y la Administración Estatal para la Industria y Comercio, que revisa acuerdos y abuso de posición dominante en casos que no sean de precios. El diseño institucional del régimen antimonopolios de China puede crear un gran número de problemas, tales como conflictos de interés, aplicación selectiva, sesgo en la investigación judicial y falta de transparencia. Véase ZHANG (2011). Estos problemas de diseño probablemente agravan el aislamiento político a las SOEs de un control antimonopolios.

77 Un ejemplo de la importancia que los gobiernos locales están dando ahora a la vinculación con los grupos nacionales: en el período de un mes en 2011, el gobierno local de Guandong (Cantón) logró 249 acuerdos de colaboración con 71 grupos nacionales, representando una inversión total de US\$40 millones. Li (2011). 
vinculan a los grupos empresariales importantes con las instituciones del gobierno central y el partido comunista. Una gran cantidad de puentes institucionales facilitan la interconectividad. El primero de ellos es la Asociación China de Grupos Empresariales (la Asociación), la que formalmente es la intermediaria entre los grupos empresariales nacionales y el gobierno central ${ }^{78}$. Es supervisada tanto por SASAC como por el Ministerio de Comercio. $\mathrm{Su}$ directorio está compuesto por altos funcionarios gubernamentales y altos ejecutivos de los grupos empresariales nacionales más importantes. La Asociación es un medio de transmisión de los asuntos de interés de los altos ejecutivos de las SOEs más importantes al Consejo de Estado. Entre los temas recientes discutidos por la Asociación se incluyen el racionalizar el proceso gubernamental de aprobación de inversión extranjera y mejorar los controles internos de riesgo en conexión con la inversión extranjera. La Asociación también hizo gestiones, en contra de una gran resistencia de los reguladores bancarios, para el establecimiento de las sociedades financieras dentro de los grupos empresariales, discutido anteriormente en la Parte II. A. ${ }^{79}$.

Un segundo puente, con un origen que se remonta al período anterior a SASAC, es la práctica de entregar amplios derechos de administración sobre una importante SOE con presencia nacional al ministerio que tiene autoridad de supervisión sobre la industria en la cual opera. Por ejemplo, el Ministerio de Industria y Tecnología de la Información conserva importantes derechos de administración sobre China Mobile, incluyendo la facultad de designar a sus altos ejecutivos, a pesar de que China Mobile es parte de un grupo empresarial nacional cuya sociedad matriz pertenece en un $100 \%$ a SASAC ${ }^{80}$. En algunas industrias los intercambios de personal de alto nivel en ambos sentidos, entre ministerios y grupos empresariales nacionales, refuerzan este vínculo ${ }^{81}$.

Un tercer puente institucional es el intercambio rutinario de personal entre SASAC y las SOEs centrales que esa supervisa. En una política diseñada para promover "la mutua adaptación en cualidades políticas y profesionales" 82 , cincuenta a sesenta ejecutivos de las SOEs son trasladados anualmente a SASAC por períodos de un año, y viceversa. La información disponible de esta práctica indica que los ejecutivos empresariales trasladados a SASAC son relativamente mayores y que se envían desde las empresas más importantes. Los funcionarios de SASAC, por su parte, son relativamente jóvenes. Esto sugiere que los intercambios de personal no están principalmente diseñados para facilitar la supervisión de SASAC sobre las SOEs, sino más bien ir construyendo la capacidad de SASAC y promover la cooperación entre el sector empresarial estatal y el gobierno.

\footnotetext{
78 Entrevista con el alto funcionario administrativo, China Group Companies Association, in Beijing, China (June 21, 2011).

79 Entrevista con el alto funcionario administrativo, China Group Companies Association, in Beijing, China (June 21, 2011).

80 Entrevista con investigador jurídico en in Beijing, China (June 2011).

81 Un ejemplo reciente es el movimiento prácticamente simultáneo en 2011 de la designación de Secretario del Partido Comunista de China Mobile del Vice Ministro del Ministerio de Industria y Tecnología de la Información, y la designación del Vice CEO de China Mobile para el cargo recién dejado vacante de Vice Ministro.

82 SHI (2007).
} 
Un cuarto puente institucional entre las grandes empresas estatales y el gobierno es la práctica de reservar un determinado número de cargos en varios cuerpos de élite (aunque funcionalmente obscuros) pertenecientes al gobierno central y al Partido Comunista para líderes de las SOEs nacionales. Los principales entre ellos son el Congreso Nacional del Pueblo, el órgano legislativo simbólico del gobierno central; la Conferencia Consultiva Política del Pueblo Chino, un cuerpo consultivo compuesto por representantes de diferentes grupos sociales y políticos; y el Congreso Nacional del Partido Comunista Chino, la asamblea general del partido. Por ejemplo, basado en un grupo de candidatos recomendados por los comités del Partido Comunista de las 120 empresas centrales existentes a la época, SASAC designó a 22 ejecutivos como representantes al actual (11\%) Congreso Nacional del Pueblo y a 99 ejecutivos a la $11^{\text {a }}$ Conferencia Consultiva del Pueblo Chino, ambas en funciones desde 2008 a 2013 ${ }^{83}$. En 2007, el Comité del Partido Comunista de SASAC y los comités del partido de las 120 empresas centrales seleccionaron a 47 miembros para el 170 Congreso Nacional del Partido Comunista Chino ${ }^{84}$. La composición de los miembros elegidos fue determinada según instrucciones del Departamento de Organización Central del Partido Comunista, las que especificaban que no más del 70\% de los puestos debería ir a los altos ejecutivos de las sociedades matrices, y no menos del $30 \%$ a ejecutivos de rango medio de las sociedades matrices y altos ejecutivos de sus subsidiarias ${ }^{85}$.

Como se explica en detalle más adelante, el partido comunista también juega un rol muy importante en la designación del personal en los grupos empresariales nacionales. Un tercio de los empleados en las SOEs nacionales son miembros del partido comunista ${ }^{86}$, y existen organismos del partido en cada uno de los niveles de jerarquía del grupo empresarial. En alguna época, puede que haya habido razones ideológicas para el omnipresente rol del partido comunista en las SOEs. Pero también es persuasiva una explicación de política económica para dicha práctica: en la época de planificación centralizada, el partido comunista constituía un enorme grupo de interés que mantenía amplios vínculos con las actividades económicas. En efecto, en esa época frecuentemente había muy poca separación entre los órganos gubernamentales, económicos y sociales, con una profunda participación del partido en las tres esferas de actividad. La societización (corporatización) y otras reformas económicas podrían haber planteado una gran amenaza al sistema de gobierno del Partido Comunista. Así, la participación institucionalizada del partido en el sector estatal posterior a la reforma económica puede ser vista como una manera de obtener su apoyo para llevar a cabo dichas reformas que de otra manera hubiese bloqueado. También, el partido está funcionalmente bien situado para supervisar al personal de las SOEs. Como dice un autor:

"El control del Partido sobre el personal estuvo en el centro de su capacidad para renovar las empresas estatales, sin perder al mismo tiempo influencia sobre ellas... El

\footnotetext{
83 SASAC (2008) pp. 81-93.

84 SASAC (2006).

85 SASAC (2008) pp. 81 y 93.

86 A fines de 2009, un número de 3,03 millones de un total de 9,36 millones de empleados de las SOEs centrales eran miembros del partido comunista. SASAC (2010b).
} 
órgano del Partido Comunista con el máximo poder sobre el personal, el Departamento de Organización Central, es sin lugar a dudas la oficina de recursos humanos más grande y más poderosa del mundo" ${ }^{87}$.

\section{Ejemplos}

Con el propósito de ilustrar lo recientemente señalado, describiremos a continuación la estructura corporativa y características de gobierno de dos grandes empresas estatales: Chinalco, uno de los productores de aluminio más grandes del mundo, y China Datang, gran productor de energía. Para como están estructuradas las grandes empresas estatales, Chinalco es excepcional y Datang pertenece a la regla general. Quisimos incluir a Chinalco para hacer un contraste y porque su estructura es un legado de una forma de alianza de negocios, frecuente en una etapa más primaria del proceso de reforma chino. Contrastando Chinalco con Datang nos ayudará a ilustrar el dinamismo de las formas organizativas en el sector estatal.

\section{China National Nonferrous Metals Industry Group}

La Aluminum Corporation of China (Chinalco) es una empresa del listado Fortune Global $500^{88}$. Sus orígenes pueden ser localizados en la Oficina de Metales No Ferrosos, formada en 1979 en el Ministerio de Industria Metalúrgica. La empresa fue reinventada varias veces hasta que en 1999 logró su actual estructura como la joya de la corona del grupo Aluminum Group Corporation of China. El grupo Chinalco ha conservado algunas características del concepto de alianza de negocios corriente en los años 80, durante el período formativo de la empresa. De esta manera, Chinalco no solo es un grupo por derecho propio, sino que también es la pieza central de una alianza más amplia de empresas, la China National Nonferrous Metals Industry Group (CNNG por su abreviatura en inglés) ${ }^{89}$. CNNG tiene cuatro niveles de empresas, organizadas para colaborar a lo largo de la cadena de producción de metales no ferrosos. Los primeros tres niveles se asemejan a la estructura de los demás grupos nacionales SOE. Ellos consisten en la sociedad matriz, Chinalco, con subsidiarias en las que tiene el $100 \%$ de la propiedad, como con otras sobre las que no tiene su control. Lo que hace especial a este grupo es el vasto cuarto nivel, que se compone de más de 100 sociedades en las que Chinalco no tiene acciones pero con las cuales ya sea Chinalco u otros miembros del grupo tienen relaciones comerciales de larga data ${ }^{90}$. Algunos miembros del cuarto nivel son también miembros de grupos empresariales locales, que actúan como puentes hacia otras redes de negocios ${ }^{91}$. Debido a que la autoridad de supervisión de SASAC se basa en la propiedad accionaria, la gran cantidad de miembros contractuales de CNNG no están dentro del sistema de gobierno de SASAC, y no cuentan

\footnotetext{
${ }^{87}$ McGregor (2010) p. 69.

88 CNN (2012) en el ranking mundial, Aluminum Corp. figuraba como la empresa número 298t.

89 CNNG es el sucesor del Aluminum Group of China (CHINALG), formado en 2003. Aunque en abril de 2007 CHINALG se transformó en CNNG, este último retuvo su estructura básica de gobierno corporativo.

90 CHINALG incluía cuatro centros de investigación, nueve joint-ventures estatales-privados y veintiuna compañías privadas.

91 Ver una Lista de los Miembros del Consejo en CHINALG (2007a).
} 
en el ranking de grupos empresariales por tamaño. En esencia, CNNG es una asociación industrial con un importante grupo empresarial con participación nacional verticalmente integrado que se encuentra incrustado en su núcleo. CNNG tiene en la actualidad 197 miembros $^{92}$, y es un híbrido entre las alianzas contractuales de los años 80 y los actuales grupos empresariales, en los que prevalece una relación jerárquica de propiedad accionaria.

Los documentos formales de gobierno corporativo de CNNG son un breve resumen del sistema de capitalismo de Estado, reflejando tanto intereses políticos como empresariales. De acuerdo a la Escritura de Constitución del Grupo, uno de los grandes objetivos de CNNG es asumir importantes funciones requeridas por el Estado, entre las cuales están la implementación de políticas nacionales de desarrollo económico, aconsejar al gobierno sobre la puesta en práctica de políticas industriales, y en implementar estándares corporativos, industriales y nacionales ${ }^{93}$. Este es un reconocimiento formal del objetivo del Estado al establecer los grupos empresariales como un mecanismo para ejercer control e implementar políticas de desarrollo a través de las redes organizadas alrededor de las sociedades matrices. La Escritura de Constitución del Grupo también señala una lógica de negocios clara y concisa para la formación de CNNG: coordinar los recursos entre las sociedades del grupo. De acuerdo a la Escritura de Constitución del Grupo, CNNG fue creado para entregar una plataforma de intercambio tecnológico, reorganizar el capital, colaborar en ventas y marketing, mejorar la asignación de recursos entre las empresas del grupo, apoyar la internacionalización de la investigación, producción y ventas de las sociedades, diseminar información dentro del grupo y coordinar las relaciones entre las compañías del grupo ${ }^{94}$.

La colaboración en políticas y recursos entre una gran cantidad de empresas requiere mecanismos de coordinación dentro del grupo. Sin embargo, la falta de vínculos de propiedad entre muchas compañías en CNNG deja al grupo sin mecanismos de derecho societario para facilitar la coordinación. En lugar de estructuras organizacionales, CNNG usa mecanismos contractuales de gobierno corporativo representando en forma clara los principios democráticos. Los asuntos internos son dirigidos por un consejo de administración compuesto por un representante de cada miembro y presidido por el representante de la sociedad matriz ${ }^{95}$. El consejo de administración tiene un comité ejecutivo de gran envergadura, compuesto por tres subcomités, para lograr la implementación de las decisiones del consejo de administración. El comité ejecutivo está compuesto no solo de representantes de la sociedad matriz y de sus subsidiarias controladas, sino que también de representantes de empresas que solo tienen una relación contractual con estas compañías. Tanto en el conse-

92 Información presentada en la Tercera Reunión del Tercer Consejo de Administración de CNNG, marzo de 2011. China Nonferrous (2011).

93 CNNG (2007) art. 7, ítems 1-3.

94 CNNG (2007) art. 7, ítems 4-8.

${ }^{95}$ CNNG (2007) art. 8. Las responsabilidades del consejo de administración incluyen el coordinar las relaciones entre las sociedades del grupo para lograr sinergias, entregar las recomendaciones de las compañías del grupo al Consejo de Estado, investigar las tendencias de los mercados doméstico e internacional y explorar los mercados internacionales, aprobar los planes estratégicos del grupo, aprobar y modificar las reglas de gobierno corporativo del grupo y aprobar los informes anuales y los estados financieros del grupo. 
jo de administración como en el comité ejecutivo, las decisiones se toman por mayoría de voto, con un voto por representante.

La estructura de gobierno corporativo de este grupo nos recuerda a los consejos de presidentes en los keiretsu japoneses ${ }^{96}$. Aunque algunos investigadores le han dado bastante importancia al consejo de presidentes como institución de gobierno corporativo, la verdad pareciese ser que dicho órgano fue usado principalmente más bien como un mecanismo de intercambio de información y para la toma de decisiones en temas no esenciales de negocios, como las relaciones públicas. No tenemos suficiente información sobre los mecanismos de gobierno entre los grupos de CNNG, los que son bastante usados, para saber cuán importante es su rol en la práctica.

\section{China Datang Group}

China Datang es una empresa de la lista Fortune Global $500^{97}$, y una de las cinco empresas generadoras de energía más grandes de China. El grupo en el que está inmerso se compone de 143 sociedades. Hemos elegido este grupo porque es típico en su clase e ilustra con precisión la jerarquía interconectada común en las más importantes SOEs chinas en la actualidad. Tiene una estructura estratificada, con la sociedad matriz en la cúspide y, hacia abajo, subsidiarias controladas directa o indirectamente por ella. También, está la naturaleza jerarquizada, de arriba hacia abajo, en la estructura de propiedad, con casi una completa ausencia de propiedad accionaria cruzada entre las compañías del grupo, el que incluye tres sociedades que cotizan en bolsa, todas controladas por la sociedad matriz. Entre ellas está Datang International Power Generation Corporation, cuyas acciones se cotizan en las bolsas de Hong Kong y Londres. Otro miembro clave es la sociedad financiera, también controlado por la sociedad matriz, con algunas acciones poseídas por las sociedades que cotizan en bolsa.

Pero China Datang Group no es autárquico. El grupo tiene amplias redes con empresas fuera de él: 84 compañías no pertenecientes al grupo tienen relaciones accionarias con sociedades del mismo. Estas redes son muy estratégicas, compuestas por empresas que operan en industrias relacionadas o complementarias. Por ejemplo, el grupo tiene empresas conjuntas de carácter accionarial (equity joint ventures) con los otros grandes grupos generadores de energía en China, incluyendo al Guodian Group, Huadian Group y Hauneng Group $^{98}$. Otra empresa conjunta de carácter accionarial se ha constituido con el Three Gorges Group, que también está activo en la generación de energía. De esta manera, las empresas generadoras de energía más grandes no solo comparten un accionista controlador común en SASAC, sino que también tienen la propiedad conjunta en varias sociedades.

\footnotetext{
96 Esta es una reunion ordinaria de los presidents de las empresas afiliadas con un grupo corporativo Keiretsu determinado.

97 CNN (2012). En el ranking mundial la empresa China Datang estaba situada en el número 369.

98 En 2002, el gobierno chino reorganizó la industria energética nacional. National Power Corporation, que controlaba la mitad de los generadores de energía y todas las redes de suministro en China, fue disuelta y sus activos divididos en 11 grupos empresariales bajo la supervisión de SASAC. Datang es una de las empresas generadoras de energía creadas en la reorganización. MA y OXLeY (2012) p. 129.
} 
Aunque el paralelo está bastante lejos de ser perfecto, hasta cierto punto, la estructura del grupo empresarial chino se parece, en su conjunto, a la estructura del chaebol coreano $^{99}$. O sea, mientras los grupos empresariales, individualmente considerados, están verticalmente integrados junto a la línea de producción y no tienen propiedad accionaria cruzada entre las sociedades del grupo, los grupos considerados bajo la supervisión de SASAC, tomados en su conjunto, se asemejan a un conglomerado gigante diversificado bajo un único accionista controlador con amplia propiedad accionaria cruzada y otras formas de colaboración entre las empresas.

\section{EL ESTADO-PARTIDO COMO ACCIONISTA CONTROLADOR}

En la cumbre de los grupos empresariales con participación a nivel nacional está SASAC, presumiblemente "el accionista controlador más grande del mundo"100. Los regímenes de accionista controlador son frecuentes en el mundo ${ }^{101}$, y en este aspecto, la clase de capitalismo de China comparte una característica importante con el capitalismo corporativo de muchos países en desarrollo o recientemente desarrollados. A diferencia del control estatal en China, en otros países, el accionista controlador generalmente es el fundador o un miembro de su familia ${ }^{102}$. Pero, como recientemente una investigadora lo ha señalado "es fácil exagerar la extensión hasta la que la que los intereses del gobierno como accionista controlador difiere de la de aquellos accionistas controladores privados"103. Esto es porque, sin considerar su identidad, todos los accionistas controladores enfrentan incentivos similares. El porcentaje de su participación conlleva el incentivo de vigilar de forma más cercana la administración, en comparación a como lo hacen los accionistas en sistemas de propiedad dispersos. Pero los accionistas controladores también tienen incentivos particulares para maximizar los "beneficios privados del control" por medio de transacciones que limitan la ganancia de los accionistas minoritarios ${ }^{104}$.

Sin embargo, las generalizaciones y comparaciones a un nivel general con otros regímenes de accionistas controladores probablemente nos inducirían a error, y ello debido a que varios aspectos del régimen chino lo hacen muy particular. Así, es único en su alcance en relación con las organizaciones que abarca. En ningún otro país, un solo accionista -privado o público- ha invertido tan dominantemente en las empresas más importantes de la economía nacional. De forma directa o indirecta SASAC es virtualmente el controlador mayoritario de todas las empresas líderes en cada uno de los sectores fundamentales de la

\footnotetext{
99 Cita 38.

100 Aguiar (2007).

101 Gilson (2006) pp. 1641, 1645.

102 Gilson (2006) p. 1660. Señalando que el 34\% de las compañías del S\&P 500 fueron fundadas como empresas familiares; Gilson y Milhaupt (2008) pp. 1345, 1346: (“[S]ome major developing countries ... increasingly reflect a form of state capitalism ... For developing economies, ... the state, acting through [sovereign wealth funds], through direct ownership of operating companies, and through regulation, seeks to level the playing field").

103 Pargendler (2012) p. 2923.

104 Pargendler (2012) p. 2923 n.1 8; p. 2924 n. 21.
} 
economía china, desde la industria de las telecomunicaciones a la energía y desde la industria automovilística hasta el hierro ${ }^{105}$. Más importante, como explicaremos más adelante, es un error atribuir a SASAC los mismos derechos de control asociados a los que tienen accionistas controladores en otros regímenes de gobierno corporativo.

\section{A. SASAC COMO CONTROLADOR}

La compleja naturaleza de los derechos de control de SASAC en las grandes empresas estatales no puede ser entendida sin al menos hacer un breve esbozo de sus comienzos. Las SOEs con presencia nacional fueron creadas formándolas desde los ministerios del gobierno central en el proceso de "societización", que transformó órganos gubernamentales en sociedades anónimas. Inicialmente, el control accionario sobre las SOEs fue entregado a los ministerios de donde habían salido, lo que de manera previsible llevó a unos resultados negativos ${ }^{106}$. El Consejo de Estado experimentó con diferentes estructuras de control para las SOEs con presencia nacional, lo que finalmente llevó a la creación de SASAC.

SASAC, constituida por el Consejo de Estado en 2003, representa un segundo intento para consolidar los derechos de control sobre las SOEs con presencia nacional. SASAC tiene una larga lista de funciones formales y responsabilidades, incluyendo las de preservar y aumentar el valor de los activos estatales, reestructurar las SOEs de rango nacional, designar y remover altos ejecutivos de las SOEs y redactar regulaciones sobre la administración de los activos de las SOEs ${ }^{107}$. Tiene una plantilla de alrededor de 800 personas, organizadas en diversas oficinas, desde reestructuración de empresas hasta relaciones internacionales ${ }^{108}$. Pero a pesar de una apariencia externa de tener un control consolidado sobre las SOEs que formalmente supervisa, SASAC es una "operación en curso", y el legado de derechos de control compartidos no se solucionó por su mero establecimiento. Esto es particularmente verdadero conociendo su ubicación en el organigrama gubernamental: aunque SASAC es un organismo de jerarquía ministerial, así son también 53 de las SOEs más importantes que están bajo su supervisión ${ }^{109}$. SASAC enfrenta una potencial resistencia tanto de las sociedades que debe supervisar como también de algunos programas competidores de

\footnotetext{
105 Dean, Browne y Oster (2010). Constatando que para el año 2008, los activos totales de las empresas estatales de China eran $\$ 6$ trillones (133\% del tamaño de la economía China), y comparando a China con Francia, otro país con una extensa participación estatal en la economía donde los activos de empresas estatales sumaron $\$ 686$ billones (alrededor de un 28\% de la economía francesa)). Las empresas SOEs bajo la supervisión de SASAC reúnen el 62\% del PIB de China. SASAC (2010d).

106 Por ejemplo, falta de mecanismos de coordinación centralizados, débil fiscalización y conflictos entre los roles de regulador y actor económico del ministerio.

107 Véase SASAC (2003).

108 SASAC no hace público su número de empleados, pero nos enteramos por medio de su oficina de relaciones públicas que este número es "confidencial". Sin embargo, un dictamen de la Unión Europea sobre antimonopolios que involucraba a una SOE china fijó el número en 800, basado en la información entregada al regulador europeo. China National Bluestar con Elkem (2011).

109 Algunos han expresado que, consecuentemente con decir que la propiedad de los activos estatales es "del pueblo", la autoridad competente sobre las SOEs debería haber sido el Congreso Nacional del Pueblo en vez del Consejo de Estado. Walter y Howie (2011) p. 167.
} 
otros ministerios importantes, como el Ministerio de Finanzas ${ }^{110}$. Como un comentarista señala, "en la práctica, SASAC ha enfrentado una ardua lucha para establecer su autoridad sobre las SOEs que supuestamente controla como representante de su propietario, el Estado"111.

Hasta hace poco, SASAC no tenía una autoridad legal de carácter general en su rol de accionista controlador. En 2008 -reveladoramente, después de un difícil proceso de balance de intereses de grupo que comenzó en $1993^{112}$ - se promulgó la Ley de la República Popular China sobre los Activos Estatales de las Empresas (Ley de Activos de SOEs) para "proteger el sistema económico básico de China..., potenciando el rol directivo de la economía de propiedad estatal en la economía nacional"113. Esencialmente, la ley reconoce formalmente a SASAC como un inversionista, un accionista en las SOEs nacionales, con los derechos y obligaciones ordinarios de un accionista. Aparentemente, la ley limita a SASAC a este rol $^{114}$, regulando sus funciones como un inversionista ${ }^{115}$. Sin embargo, no hay mecanismos formales en la ley para hacer cumplir las responsabilidades de SASAC, y en realidad, la ley entrega a SASAC poderes más amplios que los que tiene disponibles como accionista bajo la Ley de Sociedades china.

En pocas palabras, SASAC tiene como accionista controlador menos y más poder que lo prescrito por las leyes, al mismo tiempo.

\section{Derechos de control en la Administración}

Tal como los accionistas controladores en todas partes, uno de los principales poderes de SASAC en relación con las grandes empresas estatales es el nombramiento y la retribución de los altos ejecutivos. Pero SASAC ejerce este poder a la sombra del control del Partido Comunista. Como se ha señalado, varios órganos del partido tienen poder de nombramiento en las SOEs de rango nacional, anterior al establecimiento de SASAC, y esta práctica se retuvo incluso después de su establecimiento. El tener "cualidades políticas", incluyendo la pertenencia al partido, es uno de los criterios más importantes con el que se evalúa a alguien en el desempeño de su administración ${ }^{116}$.

Hay dos sistemas paralelos de recursos humanos en todas las SOEs chinas: el sistema de administración societaria normal y el sistema del Partido Comunista ${ }^{117}$. En el sistema

\footnotetext{
110 Naughton (2008).

111 Mattlin (2011).

112 En 1993 se formó un grupo de trabajo para redactar la ley. Un profesor de derecho que entrevistamos señaló que renunció al grupo de trabajo cuando se dio cuenta que la Ley SOE no iba a ser compatible con principios de gobierno corporativo de un régimen de mercado o con la Ley de Sociedades.

113 Art. 1 de la Ley de Activos de SOEs.

114 Arts. 11-14 de la Ley de Activos de SOEs.

115 El art. 69 de la Ley de Activos de SOEs, que estipula medidas disciplinarias indeterminadas contra el personal de SASAC que hubiese descuidado sus obligaciones como inversionista. El art. 70 de la misma ley somete a responsabilidad personal al representante del accionista nombrado por SASAC por las pérdidas causadas por su fracaso en poner en práctica las instrucciones de SASAC.

116 Documento No 17 de 2009.

117 Sobre el sistema de recursos humanos del Partido Comunista en general, véase Burns (1994) p. 458; CHAN (2004) p. 703; Howson (2009).
} 
de administración societaria normal, los cargos son semejantes a aquellos comúnmente encontrados en empresas de otros lugares, tales como CEO, Vice CEO, Gerente de Contabilidad, y si la empresa tiene un directorio, un presidente y directores independientes. Por otro lado, un equipo de dirigencia en el sistema del partido comunista incluye al Secretario del Comité del Partido, varios Secretarios Adjuntos y un Secretario de la Comisión de Inspección de Disciplina (un cargo anticorrupción), junto con otros miembros del Comité del Partido. La penetración institucionalizada del Partido Comunista en los roles corporativos es una política oficial, y las superposiciones entre los dos sistemas aparecen en forma bastante uniforme, tal como la del gerente corporativo de un determinado rango que por regla general tiene un cargo de rango equivalente en el sistema del partido ${ }^{118}$.

Los nombramientos societarios y los del partido comunista se llevan a cabo según un arreglo compartido altamente institucionalizado entre el partido y SASAC. Los más altos cargos en 53 empresas de rango nacional, incluyendo al Presidente del Directorio, CEOs y secretarios del partido, son nombrados y evaluados por el Departamento de Organización del Partido. Este es un legado de la práctica de nombramientos anterior al establecimiento de SASAC. Algunos de estos cargos conllevan rango ministerial equivalente a gobernadores provinciales y miembros del Consejo de Estado; otros implican un rango viceministerial. Los cargos adjuntos en estas empresas son designados por la Oficina de Construcción del Partido de SASAC (el departamento organizacional del Partido Comunista dentro de SASAC). Una sección distinta de SASAC, la Primera Oficina para la Administración de los Altos Ejecutivos, ayuda en el proceso de nominación. Los nombramientos y evaluaciones de los altos ejecutivos en las restantes empresas con presencia nacional son realizados por otra sección de SASAC, la Segunda Oficina para la Administración de los Altos Ejecutivos. Aunque el poder de nombramiento pertenece formalmente a SASAC, las decisiones sobre las designaciones se realizan con el aporte de varios órganos del partido y ministerios que supervisan las operaciones comerciales relevantes, y están sujetas a la aprobación del Consejo de Estado ${ }^{119}$.

Los nombramientos y el proceso de evaluación de los altos ejecutivos de las SOEs con presencia nacional se apoyan tanto en las recomendaciones de los ministerios como en la capacitación de liderazgo hecha por el Partido Comunista. El Departamento de Organización del Partido y SASAC compensan las asimetrías en la información sobre la capacidad e idoneidad de cada ejecutivo de las SOEs obteniendo información de los ministerios que supervisan la industria en la que opera una SOE. Además, los ejecutivos de las SOEs se

118 En 2004, el Departamento de Organización del Partido Comunista Chino y el Comité del Partido de SASAC publicaron las Opiniones Concernientes al Fortalecimiento y Mejoramiento de la Labor de Construcción del Partido en las Empresas de Rango Nacional. Un principio clave de las Opiniones es la política de "las entradas bilaterales y los nombramientos cruzados". Entradas bilaterales significa que miembros del Comité del Partido pueden prestar sus servicios en los directorios, comités de supervisión y en la alta gerencia, mientras que los miembros del directorio, comités de supervisión y los altos ejecutivos que son miembros del partido pueden entrar al Comité del Partido. Nombramientos cruzados significa que si la empresa tiene un directorio, el Secretario del Comité del Partido y el Presidente del Directorio pueden ser la misma persona. Si la empresa no tiene un directorio, entonces el Secretario del Comité del Partido puede ser el CEO, y el Vice CEO puede ser el Secretario Adjunto del Comité del Partido.

119 SASAC (2004) p. 99. 
capacitan participando en el sistema educacional del partido comunista, que sirve de think tank y centro de capacitación de mitad de carrera para los miembros del partido. El Colegio Central del Partido Comunista en Pekín, el más importante y prestigioso de estos colegios, ofrece clases de capacitación especializada para los ejecutivos de las SOEs ${ }^{120}$. Aunque existe poca información disponible sobre el contenido de esta capacitación, este sistema de colegios pareciera entregar una excelente oportunidad a la dirigencia del partido para evaluar la inteligencia, habilidades y compromiso de aquellas personas que pasan por sus programas.

Los mecanismos corporativos estándares de designación y evaluación de los altos cargos -el directorio- están completamente ausentes. De hecho, al 31 de diciembre de 2012, solo 51 sociedades matrices de los 117 grupos corporativos con presencia nacional tienen directorio $^{121}$. Aunque SASAC y el Partido Comunista han empezado a tomar medidas para incluir a los directorios dentro del proceso de nombramiento y crear directorios para aquellas sociedades matrices que todavía no los tienen, las decisiones tomadas hasta la fecha dejan pocas dudas de que el Partido Comunista no tiene la intención de ceder el poder de nombramiento en las empresas más importantes y las designaciones del más alto nivel ${ }^{122}$.

Para entender cómo el Estado-Partido controla a los ejecutivos en las grandes empresas estatales, ofrecemos a continuación información que hemos recolectado sobre nombramientos y destituciones de "líderes" de las empresas bajo la supervisión de SASAC entre 2003 y 2009. El término "líderes" es usado por SASAC para referirse a aquellos que tienen un alto rango tanto en las empresas como en el Partido Comunista. Esta información incluye un número limitado de nombramientos societarios de alto rango para los que SASAC lleva a cabo un proceso público de contratación ${ }^{123}$.

Según la información obtenida, entre un tercio y tres cuartos de las SOEs con presencia nacional tuvieron al menos un nombramiento o remoción de un líder por SASAC en los años cubiertos por los datos. SASAC no explica por qué el número de nombramien-

\footnotetext{
120 Shambaugh (2008) pp. 827, 837.

121 Xinhua News (2012).

122 En 2008, SASAC y el Departamento de Organización del Partido Comunista Chino publicaron la Guía sobre la Opiniones relativas a la Designación de Altos Ejecutivos por los Directorios de las Empresas Centrales. Estas opiniones por vez primera le dieron algún poder de nombramiento a los directorios. Sin embargo, la Guía sobre las Opiniones no cubre a los CEOs de las 53 empresas nacionales más importantes. Incluso, respecto a las demás sociedades, se requiere que el comité de nombramiento del directorio "consulte exhaustivamente" con el Comité del Partido y SASAC antes de designar al CEO. La designación preliminar debe presentarse a SASAC antes de que el nombramiento llegue a ser definitivo.

123 Desde 2003, SASAC ha invitado a postular para algunos cargos de alto rango corporativo. Desde 2003 a 2008, este proceso resultó en el nombramiento de 8 CEOs, 54 Vice CEOs, 50 gerentes de finanzas y 26 gerentes legales. Aunque el proceso de postulación está abierto al público y atrae a un gran número de postulantes, quizás era de esperar, el proceso frecuentemente (en alrededor del $40 \%$ de los casos) resulta en la designación de un persona ya empleada en la empresa, y en casi todos los casos restantes, en el nombramiento de un empleado de otra empresa bajo la supervisión de SASAC. Viendo con más detalle la información de este proceso, este nos entrega una visión en cuanto al tipo de ejecutivo visto como adecuado por SASAC. La edad media de los 115 ejecutivos nombrados a través del proceso de contratación pública es de 41 años. Casi el 90\% de los nombrados son miembros del partido comunista. La mayoría tenía un nivel universitario de educación, y más de la mitad de los designados como CEOs o vice CEOs eran ingenieros. Información recolectada de los avisos de postulación y decisiones puestas en la página web de SASAC.
} 
tos supera sistemáticamente al número de remociones. Las interpretaciones más probables son que (1) algunos nombramientos son en verdad renombramientos de los titulares del cargo sin haber sido previamente removidos, y (2) algunas empresas formaron su directorio durante ese período, creando nuevos cargos para ser nombrados.

SASAC también rota a los altos ejecutivos y directivos del Partido Comunista entre los grupos empresariales. La rotación es bastante común. Nuestro análisis de la información sugiere que casi todas las rotaciones corporativas son de directores o Vice CEOs, y que las rotaciones del Partido Comunista son para cargos menores que las de Secretario de Comité del Partido. Sin embargo, de vez en cuando SASAC ha hecho rotaciones de altos ejecutivos en sectores industriales claves. Por ejemplo, en abril de 2011, SASAC rotó a los CEOs de las tres sociedades petroleras principales, siendo cada una de ellas una sociedad Fortune Global $500^{124}$. SASAC realizó rotaciones similares entre los altos ejecutivos en el sector energético en 2008 y en el de telecomunicaciones en 2004 y 2007. Obviamente, dichas rotaciones ignoran la distinta identidad de los grupos empresariales y se saltan conceptos normales del derecho corporativo. Pero la práctica es menos discordante conceptualmente si, como hemos explicado con anterioridad, todas las SOEs con presencia a nivel nacional son vistas como un metagrupo diversificado bajo el control unitario (aunque de cierto modo atenuado) de SASAC. Nuestras entrevistas sugieren que las rotaciones son vistas, o al menos explicadas, por los actores chinos dentro del sistema como un mecanismo de supervisión en grupos sin directorios. Se dice que las rotaciones reducen la concentración de autoridad en una persona en particular en las empresas donde todavía no existen los órganos institucionalizados de supervisión ${ }^{125}$.

Los líderes también son rotados a través de los ámbitos empresariales, gubernamentales y del Partido Comunista. Esta información, junto con la del nombramiento de líderes de empresas a diversos puestos de gobierno y del Partido Comunista presentada anteriormente, es otra impactante ilustración de los puentes institucionales en funcionamiento en el sistema de capitalismo de Estado en China.

Lamentablemente, la información que tenemos disponible sobre nombramientos, remociones y rotaciones no nos permite hacer evaluaciones más detalladas sobre algunos temas importantes tales como las empresas específicas involucradas, las razones de las remociones (por ejemplo, despidos o promociones) y distinciones entre la administración de personal corporativo o del Partido Comunista. Pero tomada en su conjunto, la información disponible sugiere, en contra de algunas afirmaciones ${ }^{126}$, que SASAC ejerce derechos de control bastante amplios sobre los altos ejecutivos de las SOEs con presencia a nivel nacional (o al menos es el mecanismo a través del cual el Partido Comunista ejerce tales derechos de control), aunque poco se siguen las reglas comunes de derecho corporativo.

124 China National Petroleum Corporation (CNPC), China Petrochemical Corporation (Sinopec) y China National Offshore Oil Corporation (CNOOC). Downs y Meidan (2011) p. 3; CNN (2012). En el ranking mundial CNPC se encontraba en el $6^{\circ}$ lugar, Sinopec en el $5^{\circ}$ y CNOOC en el 101.

125 Entrevista con el alto funcionario administrativo, cita 77.

126 Walter y Howie (2011) pp. 167 y ss (expresando que SASAC es débil y que más se parece a un Departamento de Supervisión que está relacionado con las empresas que aparentemente supervisa). 
Concomitante con su poder de nombramiento, SASAC también supervisa la remuneración de los ejecutivos de las SOEs más importantes. Antes del establecimiento de SASAC, la remuneración de los ejecutivos se determinaba por las mismas SOEs, lo que condujo a una serie de problemas, como también grandes diferencias de sueldos entre las empresas $^{127}$. En 2004, SASAC introdujo un sistema para supervisar la remuneración en las empresas más importantes. Bajo este sistema, la estructura básica de la remuneración de los ejecutivos consiste en un salario base, bono de productividad e incentivos de compensación a mediano y largo plazo ${ }^{128}$. El órgano que se considera normal para determinar la remuneración de los ejecutivos en el derecho corporativo -el directorio o quizás el directorio junto con los accionistas- ha sido dejado de lado por este proceso. De hecho, hay evidencia que la compensación pagada a los ejecutivos de las grandes empresas estatales que cotizan en bolsa, que ha sido aprobada por el directorio y divulgada públicamente a los accionistas tiene algo de ficción, la verdadera compensación recibida por el ejecutivo es la señalada por SASAC ${ }^{129}$.

En China es difícil obtener información completa sobre la remuneración de los ejecutivos, y la información obtenida formalmente parece ser engañosa. Basado en reportes públicos, el ejecutivo mejor pagado en 2007 fue el Presidente del Grupo China Mobile, con 1,3 millones de yuanes chinos (alrededor de US\$176.000 a diciembre de 2007). La remuneración promedio para los CEOs de las empresas más importantes supervisadas por SASAC en 2009 fue de 600.000 yuanes chinos (alrededor de US\$ 88.000 en diciembre de 2009) ${ }^{130}$. Aunque estos salarios son obviamente muy bajos a escala internacional, deben ser entendidos en su contexto. Las cifras no incluyen una gran cantidad de regalías y privilegios que disfrutan los ejecutivos y sus familias, tales como vivienda, educación y salud gratis o a precio simbólico. También es común ver generosas cuentas de gastos corporativos y pagos complementarios a altos ejecutivos por servicios adicionales simbólicos prestados a la empresa y, más que el salario formal, pueden significar una parte mucho más grande de los ingresos del ejecutivo ${ }^{131}$. Además, en la sociedad china contemporánea, los puestos direc-

127 Basado en una investigación de SASAC, los mayores problemas incluían la falta de supervisión por el Estado, vaga correlación entre compensación y rendimiento, ningún mecanismo que induzca a un rendimiento de largo plazo y grandes diferencias salariales entre las empresas. SASAC (2004) p. 85-86.

128 SASAC emplea sistemas complejos de evaluación del personal para determinar las remuneraciones y los nombramientos y remociones. Los altos ejecutivos celebran un contrato anual de productividad con SASAC, en el que se especifican los criterios de evaluación, los puntos de referencia y las retribuciones o sanciones. Los resultados anuales de productividad se transforman en calificaciones hechas mediante letras desde la A hasta la E, y los bonos se determina de acuerdo a esas calificaciones.

129 Tanto las noticias de los medios de comunicación como nuestras propias entrevistas sugieren que a la época de admisión a cotizar acciones en las bolsas de Hong Kong y Nueva York en 2001, los ejecutivos de CNOOC, Inc., la subsidiaria principal de la sociedad de rango nacional del petróleo la compañía CNOOC, llegaron a un acuerdo interno por medio del cual ellos “donarían” la compensación aprobada por el directorio a la sociedad matriz del grupo. De esta manera, la remuneración aprobada e informada con arreglo a la legislación societaria y de valores de comercio no es la realmente percibida por los ejecutivos. La verdadera remuneración se fija por SASAC fuera del proceso señalado en la legislación societaria. Nuestra investigación preliminar sugiere que esta práctica es común.

130 Alrededor de un tercio era salario base y los dos tercios restantes variaban según la productividad. Li (2010).

131 Knowledge@Wharton (2012). 
tivos de alto nivel en cualquier ámbito atraen otras oportunidades lucrativas, una realidad sucintamente resumida en la frase "dinero por poder" ("money for power"), que escuchamos frecuentemente en nuestras entrevistas.

\section{Derechos de control en los activos estatales empresariales}

La misión central de SASAC es preservar e incrementar el valor de los activos estatales al tiempo que transforma las SOEs en empresas públicas. Desde su constitución, SASAC ha llevado a cabo una política de crear grandes empresas en cada una de las industrias clave de la economía. En época reciente, SASAC ha consolidado a las SOEs más débiles y pequeñas dentro de grupos empresariales más grandes. En el proceso, el número de SOEs bajo la supervisión de SASAC ha disminuido de 198 en 2003 a 121 en $2010^{132}$. La meta de SASAC es llegar a un número menor a 100. Simultáneamente, como atestigua la lista de Fortune Global 500, SASAC ha tenido éxito en su meta de construir conglomerados globalmente competitivos.

Esta misión central hace de SASAC una barrera en relación con la transferencia de activos empresariales del Estado. Con la promulgación de la Ley de Activos SOE, SASAC cuenta ahora con una sólida base legal para desempeñar ese rol. Bajo esta ley, las transferencias de acciones que involucren SOEs con presencia a nivel nacional requieren de la aprobación de SASAC, incluso en relación con las transacciones sobre las que no tiene derecho a veto como accionista según la Ley de Sociedades ${ }^{133}$. Algunos tribunales chinos han ratificado los derechos de control superior de SASAC bajo la Ley de Activos SOE, sosteniendo que los contratos de transferencia de acciones que se hayan celebrado sin la aprobación de SASAC son nulos, incluso cuando estén en conformidad con la Ley de Sociedades ${ }^{134}$. SASAC tiene amplios derechos de control sobre la transferencia de las SOEs.

\section{Derechos sobre los flujos de caja}

La separación de los derechos sobre los flujos de caja de los derechos de control es un problema central en los regímenes de gobierno corporativo del accionista controlador. Cuando los derechos de control del accionista exceden sus derechos sobre los flujos de caja, aumenta el problema de agencia entre el controlador y los accionistas minoritarios, creciendo su escala a medida que se agranda la brecha. Como lo señala Ronald Gilson, "supeditado a mantener control, a menor cantidad de acciones que tenga el controlador, mayor es su incentivo para extraer beneficios privados del control [beneficios del controlador que no se entregan a los accionistas minoritarios]; el incremento en productividad acrece a los ac-

\footnotetext{
132 SASAC (2004).

133 Ley de activos SOEs artículo 5. Por ejemplo, se requiere la aprobación de SASAC para la transferencia de acciones de una subsidiaria de una compañía bajo su control directo. Lıu (2008) pp. 281 a 296. Bajo principios de derecho corporativo, solo el directorio de la sociedad directamente bajo su control tiene autoridad para aprobar dicha transacción. Ley de Sociedades.

134 Zhang Buo con Beijing Jing Gong Garments Group Co. Ltd. (2009); Hunan Zhengqing Group Co. Ltd. con Chendu Yinghua Investment Co. Ltd. (2009).
} 
cionistas en proporción al número de sus acciones, mientras que los beneficios privados del control se distribuyen basados en el poder de gobierno" 135 .

En los regímenes de accionista controlador fuera del contexto de las SOEs, la separación de los derechos de control de los derechos sobre los flujos de caja, y el consiguiente potencial para extraer beneficios privados se presenta porque los controladores son capaces de aumentar el poder de voto de las acciones a través de acuerdos de propiedad piramidal y circular sobre las acciones entre las empresas del grupo. En el contexto de las SOEs, los reguladores y políticos actuando como "propietarios" en nombre del Estado pueden cosechar beneficios privados de control, que no comparten con los inversionistas financieros ordinarios, en la forma de influencia política, prestigio nacional y oportunidades para el clientelismo o la corrupción. Estos tipos de beneficios privados pecuniarios y no pecuniarios de control sobre las grandes empresas estatales están claramente disponibles a la élite administradora del Estado-Partido, y SASAC es un importante vehículo a través del cual dicho control se ejercita. Más allá de su rol como vehículo de gobierno del Estado-Partido sobre el conjunto de las SOEs más importantes, los incentivos organizativos de SASAC como el "propietario" formal de las SOEs con presencia nacional son afectados por una peculiar circunstancia histórica: sus derechos de control superan sus derechos sobre los flujos de caja porque, hasta hace muy poco, el Estado no percibía dividendos de las empresas estatales ${ }^{136}$. Esta decisión fue revocada en 2007 , con las empresas de $100 \%$ de propiedad estatal subsidiarias de SASAC - las sociedades matrices- ahora pagan dividendos al Estado, pero todavía a tasas inferiores que aquellas SOEs que cotizan en bolsa ${ }^{137}$. Además, SASAC recibe solo una parte de los dividendos percibidos por el Estado, que los usa para adquirir activos, reestructuraciones y ayudas de emergencia para empresas en problemas ${ }^{138}$. De esta manera SASAC no internaliza completamente las consecuencias financieras de sus derechos de control sobre los grandes grupos de empresas estatales, y se produce una subvención cruzada de las empresas bajo su supervisión con los derechos sobre los flujos de caja que posee.

Estos antecedentes sugieren que el grupo principal de SOEs en su conjunto, más que las empresas de manera individual, son lo más importante para SASAC al cumplir sus responsabilidades de gobierno corporativo, y ellas podrían explicar varios aspectos aparentemente enigmáticos del gobierno corporativo de las grandes empresas estatales en China. Por ejemplo, la práctica de la rotación de los altos ejecutivos entre las empresas en una misma industria tiene bastante sentido si el objetivo de maximizar la riqueza de los accionistas en las empresas individuales es menos importante para el accionista controlador que el formar varias sociedades globalmente competitivas en industrias claves. Otro ejemplo, es el fuerte énfasis que SASAC pone en la "responsabilidad social empresarial" (RSE) de las compañías bajo su supervisión ${ }^{139}$. La RSE es un tema típicamente pregonado por los sectores corporativos no accionistas o por las ONGs, no por los grandes inversionistas. Pero la

\footnotetext{
135 Gilson (2006) p. 1651.

136 Naughton (2008) p. 1. Las subsidiarias que cotizan en bolsa pagaban dividendos a las sociedades matrices, pero las sociedades matrices no pagaban dividendos al Estado.

137 Naughton (2008) p. 6.

138 Naughton (2008) pp. 6 y 7.

139 LiN (2010) p. 64; LIN (2009) p. 711; LiN (2007) p. 321.
} 
campaña de RSE de SASAC puede ser una manera de conseguir apoyo doméstico para el capitalismo de Estado, mejorar su imagen en el extranjero y justificar una administración de las SOEs que no es explicable solo bajo el punto de vista de la rentabilidad y eficiencia de las empresas individuales.

\section{B. Consecuencias}

SASAC no es solo el accionista controlador más grande del mundo, al menos en términos formales, sino también muy posiblemente el más peculiar. Deconstruyendo los derechos de control de SASAC en las empresas sobre las que aparentemente tiene la propiedad revela que es simultáneamente más débil y más poderoso que el típico accionista controlador en otros regímenes. Es más débil, porque no tiene exclusivo poder de designación de los altos ejecutivos de las empresas más importantes cuyas acciones controla y concede a otras agencias estatales -e incluso a las SOEs mismas- temas fundamentales que están fuera de su ámbito de especialización. Es más poderoso, debido al amplísimo alcance de su participación en las empresas más importantes de la economía nacional, y como resultado de sus amplios derechos de control en los activos estatales empresariales, lo que sobrepasa las normas estándar de derecho corporativo. Incluso, más allá de esta brecha existente en su estatus formal y poderes, SASAC es única como el punto focal del capitalismo de Estado en una superpotencia económica rápidamente ascendente. SASAC pareciese ser, por su diseño, otro puente institucional en la jerarquía interconectada - un vínculo de alto nivel entre las SOEs con presencia a nivel nacional y otros componentes importantes del Estado-Partido-. Ciertamente, quedan todavía muchas preguntas sin contestar sobre las operaciones internas de SASAC, las relaciones con las empresas que ostensiblemente controla y su supervisión por órganos del Partido Comunista y del gobierno.

Una clara consecuencia de toda esta estructura, aunque todas sus implicancias no lo fueran, es que: las grandes empresas estatales representan mucho más que una inversión puramente financiera para el Estado-Partido. SASAC, como la manifestación organizadora del Estado-Partido en su rol de accionista controlador, busca maximizar una serie de beneficios que se extienden desde los ingresos fiscales hasta el poderío tecnológico, y desde el soft power en el extranjero hasta la sobrevivencia del régimen en el plano interno. Como uno de nosotros lo puso recientemente en otro trabajo en el que también es coautor, en el capitalismo de Estado, "el gobierno trata de asegurar que el comportamiento a nivel empresarial produzca una maximización de beneficios económicos, sociales y políticos a nivel país"140. Naturalmente, los intereses "del país” están definidos y concuerdan con los intereses de la élite administrativa que juega roles clave en la operación y evolución del sistema.

\section{IMPLICANCIAS Y PREGUNTAS}

\section{A. IMPLiCANCIAS PARA EL ESTUDIO DEL GOBIERNO CORPORATIVO COMPARADO}

La última década de estudio del gobierno corporativo comparado ha estado dominada por dos grandes asuntos que están relacionados: cómo la ley influye las estructuras de

140 Gilson y Milhaupt (2011) p. 1346. 
propiedad societaria en el mundo, y si los sistemas globales de gobierno corporativo están convergiendo, particularmente en un modelo centrado en el accionista y orientado al mercado. En estos debates, particularmente en las obras influyentes que imponen los términos de la investigación, China destaca por su ausencia, planteando algo así como el "Problema Chino" para ambos asuntos.

\section{Derecho y Finanzas}

La ya conocida bibliografía sobre "derecho y finanzas" sostiene que la calidad de la protección legal para los inversionistas determina el grado al cual está dispersa la propiedad accionaria en un determinado país. Una legislación "deficiente" que protege muy mal al inversionista nos lleva a la concentración del capital societario; una legislación "buena" se traduce en propiedad dispersa. Los sistemas jurídicos originarios en el common law aparecen sistemáticamente proveyendo una mayor protección que los sistemas jurídicos de raigambre europeo continental, explicando grandes diferencias en las estructuras de propiedad alrededor del mundo ${ }^{141}$.

Hay bastante crítica a esta bibliografía y nosotros simplemente hacemos notar que la experiencia de China, como la de muchos países, parece concordar con la hipótesis de derecho y finanzas a nivel superficial pero nos alejamos a medida que hacemos un examen cuidadoso $^{142}$. Más allá de preguntarnos si la experiencia china apoya las predicciones de la bibliografía sobre derecho y finanzas, nosotros usamos las grandes cuestiones de ese cuerpo bibliográfico para generar preguntas sobre el rol de la ley y el legalismo en el crecimiento de las grandes y globalmente activas empresas chinas, y al menos por extensión plausible, el desarrollo de la economía de ese país.

La bibliografía de derecho y finanzas enfatiza los efectos "pegajosos" del "origen del sistema legal" de un país en la estructura de las empresas. Dejando de lado la difícil pregunta de cómo codificar correctamente las familias jurídicas que ponen obstáculos a los intentos de sustentar empíricamente esta aserción, consideremos si el acercamiento de los planificadores económicos chinos al crear las grandes empresas estatales ha estado fuertemente influenciado (o limitado) por una particular tradición de legalismo heredado del sistema jurídico europeo continental. El acercamiento chino ciertamente comparte con el

141 LA Porta et al. (1998) p. 1113.

142 Para una crítica de este enfoque, véase por ejemplo, Milhaupt y Pistor (2008) pp. 17 y ss. A primera vista, la experiencia de China cuadra confortablemente con la hipótesis. El sistema legal chino, aparentemente de origen europeo continental, es débil en cuanto a las protecciones formales que entrega a los inversionistas. El mercado accionario está poco desarrollado, las estructuras de propiedad societaria están altamente concentradas y la economía está llena de grupos empresariales. Pero como nuestro artículo lo ha señalado, grandes componentes de la estructura del capitalismo corporativo chino en la actualidad son productos de un diseño político deliberado o, al menos, de una experimentación llevada a cabo por el gobierno. Los grupos empresariales pueden haberse formado parcialmente como una respuesta a vacíos institucionales en el período inicial de reformas, pero motivos de producción y el deseo de transmitir la política industrial jugaron importantes roles en la formación de los estos grupos. Cuando el Estado decidió hacer uso del derecho societario y de otros conceptos jurídicos tales como alianzas basadas en contratos y registro de grupos empresariales para formar sus grupos, tenía la capacidad para hacerlo. De este modo, es difícil identificar defectos específicos en el derecho societario, ni menos efectos negativos que pudieran generalmente ser atribuidos al "origen” europeo continental del derecho chino, que promoviese la formación de grupos empresariales bajo el control del Estado-partido. 
sistema jurídico francés un alto grado de comodidad con la participación del Estado en la economía y con un paternalismo regulatorio ${ }^{143}$. Además, en contra de la desconfianza hacia lo grande que ha animado al derecho corporativo, al gobierno corporativo y al diseño institucional estadounidense a lo largo del siglo pasado, lo grande no solo ha sido tolerado sino que celebrado en el período de reforma económica de China ${ }^{144}$. Con un alto grado de generalización, es así posible decir que el acercamiento chino al derecho y al gobierno corporativo se identifica de alguna manera con el sistema jurídico europeo continental.

Pero si terminásemos con esa generalización no captaríamos el cuadro completo de cómo el sistema jurídico ha influido el acercamiento chino al gobierno corporativo. Los planificadores institucionales chinos han sido altamente eclécticos en relación con los modelos extranjeros que han usado para diseñar el sector estatal. En las primeras fases, y de acuerdo con lo que ya hemos señalado, los grupos empresariales japoneses y coreanos y sus instituciones relacionadas ejercieron un gran atractivo. Más recientemente, el enfoque basado en derechos y centrado en los accionistas del modelo de Estados Unidos, con su énfasis (aunque con un imperfecto historial) en rendiciones de cuentas y transparencia, ha tenido influencia en los legisladores del derecho corporativo, los planificadores de políticas públicas y los reguladores. El rol algo esquizofrénico de SASAC en la administración de las grandes empresas estatales puede ser el resultado de la mezcla de estas dos opiniones, la búsqueda de tamaño y control estatal junto con hacer hincapié en mecanismos independientes de rendición de cuentas y una observancia al menos externa a los estándares de gobierno corporativo global. En forma importante, la ausencia de un sistema legal afianzado y bien desarrollado en la época de la reforma en China puede que haya liberado las manos de los planificadores económicos para seleccionar formas de organización que pensaron eran las mejores para promover el desarrollo societario chino en una determinada época.

La bibliografía de derecho y finanzas plantea también la importante pregunta de precisamente qué aspectos del derecho societario, cuáles de sus características son claves para el crecimiento de las empresas. Para los autores de esa bibliografía, naturalmente, la respuesta es la protección al inversionista, ejecutable contra el deudor ${ }^{145}$. La bibliografía de derecho y finanzas enfatiza la protección al inversionista con la suposición razonable que el capital es un recurso generalmente escaso, de tal manera que los derechos de gobierno deben ser asignados con el fin de atraer inversiones. Pero la experiencia de China (junto con las de Corea del Sur y Japón durante sus períodos formativos de desarrollo) sugiere que cuando hay capital disponible, al menos para las empresas favorecidas por el Estado, la protección al inversionista no está entre las primeras prioridades ${ }^{146}$.

Sin embargo, la experiencia china parece confirmar la importancia de la forma corporativa para el crecimiento de la empresa y, quizás por extensión, para el desarrollo

\footnotetext{
143 Hall y Soskice (2001) pp. 1, 60 cita 42. Señalando la anterior dependencia de Francia en una amplia intervención estatal en los gobiernos corporativos.

${ }_{144} \mathrm{Hu}$ (2007) "extolling plan "to develop industries from bigness to strongness . . . and to encourage the development of internationally-competitive large business groups".

145 Véase texto de la cita 139.

146 Las limitaciones externas, tales como los mercados competitivos, pueden ser también una condición necesaria para el éxito de este modelo.
} 
económico. Hemos visto lo importante que ha sido el proceso de societización para el funcionamiento de la organización industrial en el sector estatal chino: la separación del aspecto regulatorio del operacional en el proceso de societización fue un primer paso importantísimo en el desarrollo de un sector SOE funcional ${ }^{147}$. Naturalmente, la societización por sí sola no completó la separación, y la línea entre la regulación y la operación permanece confusa en las SOEs chinas. Pero el uso de la estructura corporativa es un poderoso aliciente para el comportamiento organizativo y ha flexibilizado la estructura del sector estatal. Durante el periodo de reformas, los planificadores económicos chinos eligieron minuciosamente desde un grupo de características corporativas, haciendo un uso extensivo de la estructura jerárquica de gobierno corporativo y su existencia legal separada al formar redes de empresas que responden a la dirección del Estado-Partido en su rol de accionista controlador. Al mismo tiempo, el órgano clave de la empresa en la toma de decisiones y la supervisión, es decir el directorio, ha sido ampliamente marginado, y los mecanismos de ejecución de los derechos de los accionistas se han visto afectados. También hemos visto lo importante que han sido tanto el reordenamiento de los activos como la creación de vínculos entre las entidades societarias para la formación de industrias consideradas cruciales por el Estado-Partido. A diferencia de las primeras alianzas contractuales, la forma corporativa ha probado ser un mecanismo extraordinariamente útil para proveer al Estado chino un vehículo duradero, muy adaptable, y en cierto sentido, anónimo para la inversión y la actividad económica. De esta manera, el capitalismo de Estado chino es una poderosa confirmación de la genialidad de la forma corporativa como un vehículo para promover la iniciativa de inversión y producción. La ley societaria, sin embargo, en su finalidad de entregar un mecanismo fácil y efectivo para la protección de los derechos de los inversionistas, ha jugado un rol poco importante en el surgimiento de las grandes empresas chinas.

Indirectamente, la bibliografía de derecho y finanzas plantea una pregunta existencial sobre el vínculo entre las estructuras de propiedad corporativa y el crecimiento económico. El supuesto tácito en la bibliografía es que tal vínculo existe, y que las estructuras de propiedad dispersas producen un mejor rendimiento económico que las estructuras concentradas. A pesar de lo anterior, los grupos empresariales, la forma de estructura corporativa frecuente en los países con sistemas jurídicos "deficientes" en el mundo ${ }^{148}$, han sido los motores del desarrollo en países que siguen distintas estrategias económicas en los últimos 50 años. Estos países incluyen ahora prominentemente a China, que sigue una estrategia de capitalismo de Estado. Así, aunque la genialidad de la forma corporativa está presente en todos los milagros económicos, una "buena" ley societaria no es una condición esencial para esa genialidad; y la propiedad corporativa dispersa no es un elemento necesario para un desarrollo económico transformador ${ }^{149}$. A este respecto, la historia reciente de China

\footnotetext{
147 Parte III.A.

148 Y también en algunos países con sistemas jurídicos "buenos". Gilson (2006) pp. 1665 y 1667. Hablando las razones de la prevalencia de los regímenes de accionistas controladores en Suecia.

149 Un enfoque del tipo "primero la ley" para las inversiones y el desarrollo pudiese ser preferible en razón de su predictibilidad, transparencia y rendición de cuentas. Sin embargo, ello puede requerir demasiado tiempo $-y$ de esta manera ser políticamente imposible buscar ese enfoque- para países que están en sus primeros pasos del desarrollo. Un estado autoritario y las democracias en desarrollo manifestando un imaginativo pragmatismo en
} 
confirma las lecciones entregadas por la experiencia de Estados Unidos a fines del siglo XIX y comienzos del XX, una transformación económica pero discutida institucionalmente en la historia de Estados Unidos ${ }^{150}$.

\section{Convergencia}

Los estudios sobre derecho y finanzas han agregado combustible al debate sobre la convergencia, el que se pregunta si los sistemas de gobierno corporativo del mundo están convergiendo en un único modelo centrado en el accionista y orientado hacia el mercado. En la década desde que el debate prendió y que rápidamente llegó a un punto muerto teorético ${ }^{151}$, China ha surgido como uno de los poderes económicos más grandes del mundo. Con la ventaja de verlo en retrospectiva, parece curioso hoy el debate sobre la convergencia de fines del siglo XX. Los investigadores nunca consideraron seriamente la posibilidad que la legitimidad política interna y la influencia internacional pudiesen ser una gran meta de un régimen de gobierno corporativo ${ }^{152}$. El concepto de "beneficios privados (personales) de control no pecuniario" fue desarrollado para ayudar a explicar la persistencia de los regímenes de accionistas controladores, pero este concepto fue usado para describir la posición social e influencia de los emprendedores-fundadores dentro de la política económica nacional ${ }^{153}$. El capitalismo de Estado practicado en China difumina la distinción entre beneficios pecuniarios y no pecuniarios del control corporativo, y realza las grandes ramificaciones del soft power internacional de las estructuras de gobierno corporativo, al menos en un mundo donde el "capitalismo de Estado" le está planteando desafíos al "capitalismo de mercado".

Señalábamos al principio de este artículo que al gobierno corporativo chino se le define con frecuencia por lo que le falta en comparación con otros sistemas ${ }^{154}$. Esperamos que las secciones anteriores hayan significado un adelanto en la comprensión de sus características más allá de una referencia a lo que no es. En cuanto al debate de la convergencia, sin embargo, es importante resaltar que, sin importar hacia dónde se dirige el sistema chino, en la actualidad no calza claramente con ninguna de las clasificaciones en boga ${ }^{155}$. El gobierno

el diseño institucional pueden de manera creíble comprometerse al desarrollo y alentar la inversión sin recurso a una aplicación de la ley sin fricciones. Véase Gilson y Milhaupt (2011) pp. 271 a 281.

150 Cita 18.

151 Georgen et al. (2005) pp. 243, 245. El punto muerto está entre las teorías de dependencia del camino que predicen la persistencia de instituciones nacionales que protegen intereses creados, véase BEBCHUK y RoE (2004), contra las teorías de los imperativos del mercado que predicen la internalización global de las normas sobre la maximización de la riqueza de los accionistas, véase Hansmann y KraAkman (2004) p. 33.

152 La única bibliografía, de la que somos conscientes, que comienza a enfrentar el asunto con esta dimensión es Gordon (2004) pp. 161, 167. (Considerando el interés de Alemania en promover la integración de la UE al privatizar Deutsche Telekom).

153 Gilson (2006) pp. 1661-1664.

154 Véase texto citas 11-12.

155 Es clarividente el siguiente comentario hecho hace una década por investigadores enfocados en los mismos aspectos del sistema chino sobre los que estamos tratando: "Ni el término 'estado desarrollista' ni 'estado emprendedor' es adecuado para capturar la compleja red de intereses que ahora conectan al gobierno con las grandes empresas emergentes en China. Cualquiera sea el nombre que se elija, es evidente que ha nacido una nueva forma institucional.” Nolan y WANG (1999) pp. 169, 191. 
corporativo chino de las grandes empresas estatales no se basa en los bancos ni en las bolsas de comercio. No está orientado hacia los accionistas (shareholders) ni tampoco hacia "otros grupos de interés en la sociedad" (stakeholders), a menos que el concepto de "otros grupos de interés en la sociedad" se estire hasta incluir el partido político gobernante y al gobierno en su capacidad de formular políticas, regular y aplicar la ley. Tampoco es una economía liberal de mercado ni una economía coordinada de mercado, en relación con la bibliografía sobre "variedades de capitalismo"156. Ninguna de estas clasificaciones entrega una mayor comprensión analítica en un sistema de capitalismo de grandes empresas estatales en el que el Estado-Partido es el acreedor no preferente o privilegiado, accionista controlador, financista e ingeniero jefe de una completa coalición olsoniana que vincula los destinos económicos y políticos de un amplio conjunto de actores para el crecimiento económico nacional.

Naturalmente, las estructuras de gobierno corporativo en cada país son únicas. El punto es que los parámetros usados en las últimas décadas por los investigadores de gobierno corporativo comparado pueden llevar a los especialistas en China por caminos equivocados o, al menos, hacerles que pasen por alto fértiles terrenos de investigación. Tomando un ejemplo relevante para la pregunta de la convergencia, casi todos los académicos han asumido que el capitalismo de estado en China es transitorio, y que la velocidad de la transición estará en función de la capacidad del Estado y de la voluntad política para ir mejorando el ambiente institucional formal. En relación con lo anterior, muchos académicos han enfatizado la gran divergencia entre la ley formal y la práctica en el gobierno corporativo de China ${ }^{157}$. La brecha, según algunos comentaristas, se cerrará cuando China llegue a ser un país en el que se "respeten más las leyes"158.

Nuestro análisis del gobierno de las SOEs, sin embargo, apunta a un mayor ajuste entre el derecho y la práctica. Existe ciertamente una gran distancia entre la ley y la práctica en el capitalismo de estado de China si uno se centra en el derecho societario y sus instituciones relacionadas. La participación directa del Partido Comunista en el nombramiento de los altos ejecutivos, la práctica de SASAC de circunvalar al directorio en los procesos de nombramiento y remuneración, y su poder de veto sobre las transacciones societarias, son todas actividades contradictorias con principios básicos del derecho societario. Ellas también infringen reglas de soft law sobre gobierno corporativo de las SOEs promovidas por

156 Hall y Soskice (2001) p. 8. Un intento de analizar China usando la categoría de variedades del capitalismo, véase WitT (2010). Es dudosa la utilidad del marco de las variedades de capitalismo aplicado a China: el autor concluye que algunos aspectos del capitalismo chino se parecen a un sistema económico liberal de mercado, otros se parecen a un sistema económico coordinado de mercado, y todavía otros son cualesquiera de los dos sistemas dependiendo de la amplitud con que se ha definido el sujeto.

157 Clarke (2010) pp. 75, 101-102. "La realidad del gobierno corporativo en China es muy diferente de lo que aparece en las leyes, y de hecho es tan opaca que es difícil evaluarla dónde está de manera fidedigna, mucho menos saber en qué dirección se está moviendo"; Wiтt (2010) pp. 12-13.

158 Wiтt (2010) pp. 12-13, la bibliografía de las variedades del capitalismo original (que no influyó en China) fue basada en una muestra de "sociedades apartadas de la ley". Un análisis del capitalismo chino deberá tomar en cuenta el capital social como un medio para entender la divergencia entre las estructuras formales y la práctica en China. 
organizaciones internacionales tales como la $\mathrm{OECD}^{159}$. Pero si uno se enfoca en las normas que regulan la formación de grupos empresariales y su gobierno corporativo, y la Ley de Activos de SOEs que regula a SASAC en su rol formal como accionista controlador sobre las grandes empresas estatales ${ }^{160}$, la brecha entre la ley y la práctica en el sector SOE chino se acorta sustancialmente. El entorno legal de la China de hoy es en realidad bastante complementario a su actual sistema económico, en el que el sector estatal está avanzando sobre el sector privado.

Cualesquiera sean sus desventajas, y ellas son probablemente sustanciales, el capitalismo de estado en China de los últimos 30 años, representa una forma de organización industrial que produce cuantiosos beneficios a los miembros de la coalición englobante -la élite administradora con control sobre la formación e implementación de la política económica dentro del sistema Estado-Partido-. Las grandes empresas estatales, por sí mismas, son ahora jugadores importantes en la política económica china. No necesitamos mirar más allá de la experiencia histórica de Estados Unidos para ver que las grandes empresas -incluso aquellas que no están vinculadas con el Estado- pueden ejercer una gran influencia en el diseño de las instituciones nacionales y en la naturaleza de las relaciones sociales ${ }^{161}$. Por tanto es bastante posible que las instituciones jurídicas formales de China puedan "mejorarse" en una manera que refuerce el actual sistema de organización industrial en vez dar lugar a una transición hacia diferentes formas de organización corporativa. El capitalismo de Estado puede resultar un arreglo institucional duradero como resultado de las políticas de los grupos de interés, las políticas públicas y la dependencia del camino.

De esta manera, para el debate de la convergencia, China plantea la posibilidad de una nueva, durable y posiblemente influyente variedad del capitalismo. El sistema chino ya ha logrado atraer la atención, como un modelo de intervención política en la economía, de países con tradiciones políticas autoritarias, siendo Rusia el principal exponente ${ }^{162}$. Por supuesto, la imitación del modelo chino puede resultar difícil por un buen número de razones. Pero como hemos visto, las empresas chinas han entrado a la economía global a través de un camino que casi no tiene ningún parecido con la forma institucional de cómo las empresas crecen y de cómo se desarrollan las grandes economías. Así, incluso si no se imitase en otro lugar, la especie de capitalismo de China puede resultar influyente en países en los cuales falten las bases institucionales formales del crecimiento $^{163}$. Independientemente de estas formas de influencia, es evidente que el ascenso de China es una fuerza perturbadora importante del capitalismo global, que ha trastrocado nociones sobre la naturaleza del

159 Por ejemplo, las Directrices de la OECD sobre Gobierno Corporativo en las Empresas Estatales (2005) estipulan que las SOEs no deben estar exentas de la ley antimonopolios, deben enfrentar condiciones de competencia en relación con el acceso a fondos, deben establecer procesos transparentes en el nombramiento de directores y deben permitir al directorio el ejercicio de sus responsabilidades en forma independiente, incluyendo el poder de nombrar y destituir al CEO.

160 Partes II.B y III.A.

161 Cita 18.

162 LeVy (2009) p. 8.

163 Gilson y Milhaupt (2011) pp. 271 a 281. 
capitalismo que previamente estaban bien establecidas ${ }^{164}$, y ha desencadenado una reacción adversa previsible en algunas esferas ${ }^{165}$. Son profundos los desafíos que plantea un sistema económico en el que, para muchas de las empresas más grandes y más activas globalmente, es el país la unidad de maximización. Como mínimo, el ascenso económico global de China, como el de Japón hace dos décadas, probablemente va a alentar la reconsideración de vínculos de cooperación entre el Estado y el sector privado, y reenfocar la atención en clases de capitalismo corporativo interconectado. En el gobierno corporativo, como en política, no se vislumbra el "Fin de la Historia".

\section{B. Preguntas para el futuro}

Si el sistema actual representase un equilibrio relativamente estable, opuesto a un mecanismo transitorio, ¿fuera de un cambio de régimen político, qué fuerzas, pudiesen ser desestabilizadoras para dicho sistema? Estudiamos algunas posibilidades más abajo. Tal como el cúmulo de signos de interrogación lo sugiere, el debate pretende identificar posibles caminos de cambio y destacar áreas para seguir investigando; no pretendemos entregar predicciones.

\section{1. ¿Reforma legal?}

Como se ha señalado anteriormente, la actual estructura del capitalismo corporativo de China es una decisión política consagrada en la ley, hasta la fecha, una decisión muy exitosa si la medimos en función de los objetivos primarios del régimen, que incluyen un crecimiento económico sostenido, influencia internacional y sobrevivencia y legitimidad del régimen. ¿En qué dirección irán las futuras reformas a la ley de sociedades y a la de mercado de valores en el Estado capitalista chino? Nuestro artículo al menos sugiere la posibilidad de que las futuras reformas van a aumentar y legitimar el control estatal sobre importantes activos societarios en vez de dirigirse hacia estructuras de propiedad dispersa y de una reducida participación política en el gobierno corporativo ${ }^{166}$. Como lo hemos demostrado en relación con los grupos de las grandes empresas estatales, a veces se hace caso omiso, en puntos clave, de principios de derecho societario para asegurar la continuidad del control del Estado-partido. En el futuro, más directorios podrían ser designados por las sociedades matrices de los grupos de las grandes empresas estatales, los directorios de las SOEs podrían tener algo más de poder y podría ser más frecuente el nombramiento de directores independientes. Estas son reformas sobre las que han estado pendientes muchos investigadores del derecho societario. Pero ellas difícilmente alterarán las normas fundamentales del gobierno corporativo de las SOEs chinas, las que han sido establecidas por el Estado-Partido en su rol de accionista controlador.

\footnotetext{
164 Para interesantes comentarios, véase en general, Fligstein y Zhang (2011) p. 39; Lin (2011) p. 63; MeYer (2011) WALDER (2011) p. 19.

165 Dean et al. (2010) p. 1; Bremmer (2010).

166 La aplicación de la ley antimonopolios es un asunto distinto. Si el régimen antimonopolios fuese aplicable a las grandes empresas estatales, sería prácticamente imposible la actual estructura de capitalismo de estado. Por esa misma razón, es casi inconcebible que la ley antimonopolios se aplique vigorosamente al sector público sin un gran cambio en el sistema político.
} 
Naturalmente, esto no significa que las reformas a la ley de sociedades, a la de mercado de valores y los esfuerzos por la aplicación de las leyes no tengan trascendencia. Se están realizando mejoras graduales en el ambiente institucional del gobierno corporativo en China, y tienen el potencial de mejorar el gobierno corporativo en las SOEs. Pero el impacto más grande de la reforma legal puede estar no en llevar más orientación de mercado al sector público, sino en crear el ambiente institucional en el que las empresas que no tengan acceso a la red del Estado-Partido puedan obtener capital y crecer, logrando disminuir a la larga la importancia de las grandes empresas estatales en la economía china.

\section{2. ¿SASAC como Temasek?}

Otro posible camino de cambio es la reorientación del Estado-Partido en su rol de accionista controlador. Los modelos económicos extranjeros que China ha tratado de imitar han cambiado con el tiempo. Como ya lo hemos dicho, Japón y Corea del Sur fueron alguna vez importantes modelos para la construcción de los grupos empresariales bajo control estatal. Hoy en día, la sociedad holding estatal de Singapur, Temasek, es el modelo favorito de los planificadores económicos chinos. Temasek, de completa propiedad del Ministerio de Finanzas de Singapur, tiene una gran participación en el capital de muchas empresas singapurenses. Tiene la responsabilidad constitucional "de... proteger los activos y reservas claves del país"167. Su directorio es nombrado por el Ministerio de Finanzas con acuerdo del Presidente, y está compuesto en su mayoría por directores no ejecutivos, todos empresarios, incluyendo en la actualidad a un hombre de negocios extranjero. Ningún funcionario de gobierno es miembro del directorio, aunque la CEO y Directora Ejecutiva de Temasek es la esposa del Primer Ministro ${ }^{168}$. Públicamente, Temasek afirma que solo ejerce los derechos de un inversionista y la de dejar la administración de las empresas en cartera a sus respectivos directorios ${ }^{169}$. Sin embargo, Temasek mantiene fuertes lazos con el partido gobernante, el Partido de Acción Popular, que ha presidido el desarrollo económico del país ${ }^{170}$.

Una reorientación de SASAC hacia el modelo Temasek requeriría una relajación de la participación del partido en el nombramiento de los altos ejecutivos y una entrega adicional del control que ejerce sobre las grandes empresas estatales a inversionistas externos y directores independientes. Podría mejorar la transparencia y el Estado de Derecho del Capitalismo de Estado chino, reduciendo la participación del Estado-Partido en la administración de las SOEs ${ }^{171}$.

167 Temasek (2012) p. 45. Las reservas pasadas son el exceso de los activos del gobierno de Singapur sobre sus responsabilidades legales, sin considerar aquellos acumulados durante el gobierno actual. CHEw (2009).

168 Temasek (2012) pp. 44, 48, 52 y 53; Weвв (2007).

169 Temasek (2012) p. 46.

170 Mauzy y Milne (2002) pp. 28-30, 71-77. (Tratando sobre Temasek en relación con "las compañías vinculadas con el gobierno" y el partido gobernante en Singapur).

${ }^{171}$ De una manera similar, un informe reciente de alto nivel sugiere que SASAC debería limitarse a diseñar políticas públicas y a la supervisión, dejando la administración de los activos estatales a profesionales, empresas de administración de activos estatales que adhieran a principios de mercado y a estándares internacionales de transparencia. Véase Banco Mundial y Centro de Investigación del Desarrollo del Consejo de Estado de China (2012) p. 119. 


\section{3. ¿El gran giro?}

La coalición englobante de las élites administrativas chinas ha estado de acuerdo hasta aquí en una represión financiera. El sistema financiero sirve bastante bien los intereses de las grandes empresas estatales, pero atiende muy mal a la empresa privada ${ }^{172}$. Sin embargo, la historia demuestra que los países pueden experimentar dramáticos giros basados en cambios en el alineamiento político ${ }^{173}$. Como Raghuram Rajan y Luigi Zingales lo han mostrado, esos giros en el siglo XX llevaban con frecuencia una represión del sistema financiero, y ello porque los operadores históricos impedían las reformas que hubiesen entregado acceso al capital a potenciales competidores ${ }^{174}$. Pero los giros no siempre van en la misma dirección. Como tales autores señalan, en Japón, el gobierno tomó bajo su control el sistema financiero durante la guerra, para el gran beneficio de los grandes bancos japoneses durante la mayor parte del período de posguerra. Pero el sistema se desarmó en los años 80 , cuando las mejores empresas se fueron del muy regulado sector financiero doméstico hacia los mercados financieros internacionales ${ }^{175}$.

Hasta la fecha, se ha prestado relativamente poca atención en cómo impacta el sistema financiero chino a las estructuras societarias y al gobierno corporativo. ¿Buscarán algunos ejecutivos de las grandes empresas estatales una mayor autonomía financiera de los bancos estatales, particularmente si los problemas de cartera vencida acumulada y mala asignación de capital por el sector bancario lleven a una relación de mayor distancia con las SOEs? (Esto fue esencialmente la chispa del gran giro de Japón en los años 90). ¿Podrán las empresas privadas innovadoras, que frecuentemente cotizan en bolsas extranjeras debido a restricciones en el mercado doméstico de valores, generar presión en los reguladores chinos para liberalizar el mercado de capitales de modo que disminuya el rol de los bancos? Alternativamente, ¿los crecientes vínculos entre las grandes SOEs y los bancos estatales profundizarán la coalición existente a favor de la represión financiera? Cualquiera de estos potenciales desarrollos en el sector financiero podría tener profundas consecuencias para el capitalismo de Estado chino. Desde luego, la historia nos enseña que puede haber una caída u otra sacudida inesperada en caso de precipitar una realineación de la coalición o de desencadenar reformas que cambien fundamentalmente la orientación del sistema chino de gobierno y finanzas corporativas ${ }^{176}$.

\section{4. ¿"Desintegración” de los grandes grupos empresariales estatales?}

La bibliografía reciente ha destacado la forma como el rápido cambio tecnológico ha llevado a una "desintegración vertical" corporativa. Cuando una empresa determinada no puede mantenerse a la cabeza de todas las tecnologías requeridas para producir productos

\footnotetext{
172 Witt y Redding (2013) pp. 5 y 6. Contrastando el aporte de capital a las SOEs y a las empresas privadas del sistema financiero chino.

173 Rajan y Zingales (2003) pp. 5 y 21.

174 Rajan y Zingales (2003) p. 7.

175 Rajan y Zingales (2003) pp. 39 a 41.

176 Esta fue esencialmente la experiencia de Corea del Sur después de la crisis financiera asiática. Los problemas económicos de Japón, que comenzaron con una debilidad en el sector bancario, son también potencialmente instructivos para China. Véase Schuman (2011).
} 
avanzados, la colaboración entre empresas basada en un contrato puede surgir como una alternativa a la integración vertical ${ }^{177}$. Este fenómeno tiene interesantes potenciales implicancias para los grandes grupos empresariales estatales chinos. En la actualidad, los grupos están integrados verticalmente, aunque como hemos mostrado, los grupos parecen lograr los beneficios de una producción colaborativa a través de contratos y alianzas basadas en la propiedad.

El futuro de la estructura del capitalismo de los grandes grupos empresariales estatales puede depender del éxito de la actual red de empresas estatales en promover la innovación y difundir el conocimiento, incluyendo la colaboración internacional. ¿En su presente configuración puede el actual sector estatal generar tecnología de punta en todos los dominios requeridos para producir productos globalmente competitivos, y moverse a través de la frontera tecnológica de cara al aumento del costo de la mano de obra doméstica? Los cambios en las estructuras de gobierno corporativo entre las empresas impulsados por imperativos de los negocios globales podrían producir nuevas estructuras a nivel societario y colaboraciones entre las empresas que transformen la actual jerarquía vinculada a través de redes y ejercer presión en los puentes sobre los altos ejecutivos y sus supervisores del Estado-Partido. Las colaboraciones transfronterizas pueden ser mecanismos particularmente potentes para el cambio en este sentido.

\section{IMPliCACiONES PARA EL SISTEMA JURÍdico de Estados Unidos}

En el presente, las SOEs chinas son actores cruciales de la economía global, fuentes potenciales importantes de inversión extranjera directa en Estados Unidos, y fuertes competidores de las empresas estadounidenses y de otras alrededor del mundo. Esto plantea una pregunta básica para los legisladores de Estados Unidos y para las autoridades políticas de otros países: ¡las leyes que actualmente regulan la actividad en el mercado consideran adecuadamente una economía en la que las empresas de propiedad estatal o controladas por el estado son actores importantes?

En algunas áreas específicas de las leyes estadounidenses se han abordado estos asuntos. Por ejemplo, el Departamento de Justicia, con apoyo de la Judicatura, considera que bajo la Ley sobre Prácticas Corruptas en el Extranjero (Foreign Corrupt Practices Act), el soborno a un empleado de una SOE es un pago indebido a un funcionario gubernamental extranjero $^{178}$. Y en una reciente enmienda al régimen de análisis de inversión extranjera estadounidense conocido como el proceso ante el Comité de Inversiones Extranjeras en Estados Unidos (CFIUS, acrónimo en inglés), el Congreso ha resuelto varias áreas de ambigüedad con respecto a adquisiciones de empresas estadounidenses por compañías controladas gubernamentalmente ${ }^{179}$.

\footnotetext{
177 Gilson et al. (2009) pp. 431, 436 a 443.

178 U.S. v. Aguilar (2011).

179 Véase la Ley sobre Seguridad Nacional en Relación con la Inversión Extranjera de 2007. Requiriendo una investigación automática de 45 días en caso de adquisición de una empresa estadounidense por "una entidad controlada gubernamentalmente".
} 
En otras áreas importantes, sin embargo, puede ser necesario reexaminar la idoneidad del actual régimen jurídico frente a la actividad de las SOEs chinas en el mercado. Sin pretender entregar una lista exhaustiva, ofrecemos tres ejemplos de posibles brechas o incertidumbres en importantes esquemas de regulación económica. Primero, ¿entrega a los inversionistas el régimen de divulgación de información de la ley federal de valores de comercio un cuadro completo y preciso de la propiedad y gobierno corporativo de las SOEs chinas? Esta pregunta es importante tanto cuando se cotizan las acciones de una SOE china en una bolsa de comercio de Estados Unidos, como cuando la SOE china adquiere acciones de una sociedad estadounidense que cotiza en bolsa. Problemas con sociedades chinas que cotizan en los mercados de valores de Estados Unidos a través del denominado proceso de "fusión inversa" han generado bastante escepticismo sobre la calidad de las prácticas de auditoría y la exactitud de la revelación pública de información de las empresas chinas que acceden a los mercados de capitales de Estados Unidos ${ }^{180}$. Aunque las SOEs chinas no han cotizado valores en bolsa a través de fusiones inversas, estos problemas ponen de relieve potenciales insuficiencias en el régimen estadounidense de cotización y revelación pública de información en relación con los emisores chinos. Con respecto a inversiones en valores de comercio de empresas de Estados Unidos, el régimen de divulgación pública de información de la Ley Williams ${ }^{181}$ debe ser reexaminado para asegurar que está adecuadamente diseñada para lograr la revelación de toda información material sobre un accionista estatal o controlado por el Estado, particularmente cuando el accionista pueda estar invirtiendo concertadamente con otras entidades bajo el control último del Estado.

Segundo, ¿está el régimen antimonopolios convenientemente equipado para evaluar en forma precisa los efectos competitivos del comportamiento de las SOEs en los mercados de Estados Unidos? ¿Cuál es la unidad relevante de análisis al considerar los efectos en el mercado de la actuación de las SOEs, una empresa específica, el grupo empresarial al que pertenece, o el conjunto de grupos bajo control común de un accionista estatal? La Comisión Europea parece haber adoptado un enfoque acertado a este problema. En dos casos recientes que involucraban a SOEs chinas, la Comisión "indagó profundamente en... [la] relación de las SOEs con el Estado chino"182. En esos casos, la Comisión consideró que ya que las SOEs son de propiedad del Estado chino, es necesario evaluar si la SOE es una entidad independiente o si pertenece a un grupo más grande, incluyendo otras empresas sobre las que el Estado ejerce una influencia decisiva ${ }^{183}$.

Tercero, ¿cuál es el verdadero ámbito de aplicación de los tratados de inversión en los que Estados Unidos es parte? Los tratados bilaterales de inversión (TBI) generalmente tienen reglas de resolución de conflictos inversionista -Estado, pero no Estado- Estado. Cuando una inversión es hecha por una empresa estatal o controlada por el Estado ¿debe esa entidad ser caracterizada como "inversionista" para los efectos del tratado, de tal manera que una disputa relacionada con la inversión se enmarque dentro del ámbito de los proce-

\footnotetext{
180 Véase, por ejemplo, MacMahon y Ackerman (2011).

181 15 U.S.C. $\$ \$ 781,78 \mathrm{~m}, 78 \mathrm{n}(2011)$.

182 Hermert Smith LLP (2011).

183 China National Bluestar/Elkem (2011); DSM/Sinochem/JV(2011).
} 
dimientos del TBI? ¿O es la disputa más correctamente caracterizada como una entablada entre estados, y por lo tanto fuera del alcance del TBI? ${ }^{184}$.

Como ilustran estos breves ejemplos, dada la creciente interacción de las SOEs chinas en la economía global, evaluar la suficiencia de las leyes estadounidenses que regulan la actividad en el mercado de las empresas estatales o controladas por el Estado requiere una comprensión profundamente contextualizada de la estructura organizativa de los grupos empresariales chinos y su relación con el Estado.

\section{CONCLUSIÓN}

En este artículo, hemos tratado de dilucidar el "Capitalismo de Estado" en China por medio de un análisis de las estructuras de propiedad de los grupos corporativos dentro de las empresas nacionales de propiedad estatal y presentar los mecanismos que ligan a las grandes empresas estatales con los órganos del Estado-partido. Cambiando la perspectiva desde los problemas de agencia en las empresas individuales que cotizan en bolsa hacia las redes de empresas enmarañadas en órganos del Estado-partido nos ha permitido avanzar en varios objetivos importantes. Ha entregado una mejor comprensión del sector estatal chino y el entramado que apoya un componente central del modelo de desarrollo económico estatista. Ha llevado a contrastar la dimensión corporativa de la experiencia china de desarrollo con importantes debates recientes en la bibliografía. Ha entregado nuevas perspectivas en el futuro camino institucional de desarrollo de China. Y ha planteado importantes preguntas sobre la suficiencia de las estructuras regulatorias de los mercados estadounidenses para hacer frente a la inversión y a otras actividades del mercado realizadas por las SOEs chinas, un nuevo y globalmente importante tipo de actor económico.

Este esfuerzo inicial de comprender los contornos de la organización industrial en el sector de las SOEs chinas, plantea muchas interrogantes. Por mencionar solo algunas: ¡está el gran y creciente rol de las SOEs excluyendo a las empresas privadas, en un detrimento a largo plazo, del emprendimiento, innovación y de la asignación eficiente del capital en la economía china? ¿Cómo es la dinámica de gobierno corporativo en áreas claves tales como: incentivos de administración, controles internos y disciplina de los mercados de capitales, afectadas por la profunda presencia del gobierno y el Partido Comunista en las SOEs? ¿Cómo influye en el desarrollo de la institucionalidad china los estrechos vínculos entre las SOEs y aparato regulatorio del Estado-partido?

Pese a que este artículo no intenta responder todas estas importantes preguntas, entender la estructura organizativa de las SOEs chinas, sus conexiones y sus vínculos con el Estado-Partido es un primer paso esencial para analizar estos temas. En ese sentido, esperamos que nuestro proyecto haya sido un aporte para la futura investigación en esta característica fundamental de la economía política contemporánea de China.

184 Para un análisis de este tema, véase Feldman (2012) pp. 615 a 617. 


\section{BIBLIOGRAFÍA CITADA}

Aguiar, Marcos et al. (2007): "China's Megashareholder". The Boston Consulting Group. Disponible en: <https:/www.bcgperspectives.com/content/articles/globalization_strategy_sasac_chinas_megashareholder/> [fecha de consulta: 20 de septiembre de 2012].

Allen, Franklin et al. (2005): "Law, Finance, and Economic Growth in China", The Journal of Financial Economics, vol. 77 No1: pp. 57-116.

Allen, Franklin et al. (2009): "Law, Institutions, and Finance in China and India", en Eichengreen, Barry et al. (edit.), Emerging Giants: China and India in the World Economy (New York, Oxford University Press) pp. 125-183.

Allen, William y SHEN, Han (2013): “Assessing China’s Top-Down Securities Markets”, en Fan, Joseph P. H. y Morck, Randall (edit.), Capitalizing China (Chicago, The University of Chicago Press) pp. 149-200.

Aoki, Masahiko, Patrick, Hugh y Sheard, Paul (1994): “The Japanese Main Bank System: An Introductory Overview”, en Aoki, Masahiko y Patrick, Hugh (edit.), The Japanese Main Bank System: Its relevance to Developing and Transforming Economies (New York, Oxford University Press) pp. 1-50.

Banco Mundial y Centro de Investigación del Desarrollo del Consejo de Estado de China (2012): China 2030: Building a Modern, Harmonious, and Creative HighIncome Society (Washington, The World Bank). Disponible en: <http://www.worldbank. $\mathrm{org} /$ content/dam/Worldbank/document/China-2030-complete.pdf> [fecha de consulta: 5 de enero de 2013].

Beвснuк, Lucian Arye y Roe, Mark J. (2004): “Theory Of Path Dependence In Corporate Ownership And Governance", Convergence and Persistence in Corporate Governance, vol. 69.

Berle, Adolf A. Jr. y Means, Gardiner C. (1932): The Modern Corporation and Private Property (New York, Macmillan Co.).

Bremmer, Ian (2010): The End of the Free Market: Who Wins the War Between States and Corporations? (New York, Portfolio [Penguin Group]).

Bremmer, Ian y Stewart, Devin T. (2010): “China's State Capitalism Poses Ethical Challenges”. Asia Times, China Business, 17 de agosto de 2010. Disponible en: <http://www. atimes.com/atimes/China_Business/LH17Cb01.html> [fecha de consulta: 20 de septiembre de 2012].

Burns, John P. (1994): "Strenghthening Central CCP Control of Leadership Selection: The 1990 Nomenklatura", The China Quarterly, No 138, junio de 1994: pp. 458-491.

Chan, Hon (2004): "Cadre Personnel Management in China: The Nomenklatura System 1990-1998”, The China Quarterly, vol. 179, septiembre de 2004: pp. 703-734.

CHew, Valerie (2009): National Reserves (Net Assets). Disponible en: <http://infopedia. nl.sg/articles/SIP_1487_2009-03-17.html>, [fecha de consulta: 7 de noviembre de 2012].

China Bohai Bank Co., Ltd. (2012) Summary of Annual Report 2010 (China) 36 pp.

China Enterprise Management Annual Editorial Board (2010): China Enterprise Management Yearbook 2010 (Beijing, China Enterprise Management Publishing House). 
China Nonferrous (2011): Quanli dazao yiliu qiye jituan - Zhongguo youse gongye jituan san jie sanci guan wei hui zaijing zhaokai [Construir un grupo empresarial de primera clase - Tercera Reunión del Tercer Consejo de Administración de CNNG]. Disponible en: <http://www.chalco-qhb.com/hy_show.asp?id=3100> [fecha de consulta: 7 de noviembre de 2012].

Chinalg (2007a): Zhongguo lü ye jituan changwei zucheng qingkuang [Lista de los Miembros del Consejo] (Beijing, CHINALG). Disponible en: <http://www.chalco.com.cn/zl/ $\mathrm{html} / 40 / 2007 / 20071015154208781539156 / 20071015154222828274339 . p d f>$ [fecha de consulta: 30 de septiembre de 2012].

Chinalg (2007b): Zhongguo lü ye jituan gaikuang [Visión general de CHINALG] (Beijing, CHINALG). Disponible en: <http://www.chalco.com.cn/zl/html/40/2007/20071015 $154236016590199 / 20071015154258391709486 . p d f>$ [fecha de consulta: 30 de septiembre de 2012].

Clarke, Donald (2008): "The Role of Non-Legal Institutions in Chinese Corporate Governance” en Kanda, Hideki; Kim, Kon-Sik; y Milhaupt, Curtis J. (edit.), Transforming Corporate Governance in East Asia (Abingdon, Inglaterra, Routledge) p. 168-192.

Clarke, Donald (2011): "Nothing but Wind? The Past and Future of Comparative Corporate Governance", American Journal of Comparative Law, vol. 59 No 1: pp. 75-110.

CNn (2005): "Global 500: Countries, Fortune" Disponible en: http://money.cnn.com/ magazines/fortune/global500/2005/countries/C.html [fecha de consulta: 7 de junio de 2013].

Cnn (2011): “Global 500 2011: Countries-China, Fortune” Disponible en: <http://money.cnn.com/magazines/fortune/global500/2011/countries/China.html> [fecha de consulta: 7 de junio de 2013].

CnN (2012): "Global 500-Countries: China, Fortune". Disponible en: <http://money.cnn. $\mathrm{com} / \mathrm{magazines} /$ fortune/global500/2012/countries/China.html> [fecha de consulta: 7 de junio de 2013].

CNng (2007): Escritura de Constitución del Grupo CNNG (Beijing, CNNG).

Comité del Partido Comunista de SASAC (2006): Guanyu Zuohao Zhongyang Qiye Xitong (Zaijing) Shiqida Daibiao Houxuanren Tuijian Gongzuo de Tongzhi [Aviso sobre la Labor de Nominar a los Miembros del $17^{\circ}$ Congreso Nacional del Partido Representando al Sistema de Empresas de Rango Nacional (con base en Beijing)] (Beijing, SASAC, diciembre de 2006).

Congreso Nacional del Pueblo (1996): Guanyu Guomin Jingii he Shehui Fazhan "Jiu Wu" Jibua he 2010 Nian Yuanjing Mubiao Gangyao de Baogao [Informe Resumido del 9o Plan Quinquenal de la Economía Nacional y Desarrollo Social y la Perspectiva y Metas al 2010] (Beijing, 4ta Reunión del 8º Congreso Nacional del Pueblo del 17 de marzo de 1996).

Consejo de Estado de China (1987): Informe de Trabajo del Gobierno (Beijing, 5a Reunión del $6^{\circ}$ Congreso Nacional del Pueblo del 25 de marzo de 1987).

Dean, Jason, Browne, Andrew y Oster, Shai (2010): “China's 'State Capitalism' Sparks a Global Backlash”, The Wall Street Journal, 16 de noviembre de 2010. Disponible en: 
<http://online.wsj.com/article/SB10001424052748703514904575602731006315198. html> [fecha de consulta: 7 de junio de 2013].

Downs, Erica y Meidan, Michal (2011): "Business and Politics in China: THe Oil Execitive Reshuffle of 2011”, China Security, No 19.

Feldman, Mark (2012): “The Standing of State-Owned Entities under Investment Treaties”, en Sauvant, Karl (edit.), Yearbook on International Investment Law and Policy 2010-2011 (New York, Oxford University Press).

Fligstein, Neil y Zhang, Jianjun (2011): “A New Agenda for Research on the Trajectory of Chinese Capitalism", Management \& Organization Review, vol. 7.

Gabrielle, Alberto (2010): “The Role of the State in China's Industrial Development: A Reassessment, Comparative Economic Studies, vol. 52 No 3: pp. 325-350.

Gilson, Ronald J. y Roe, Mark J. (1993): “Understanding the Japanese Keiretsu: Overlaps between Corporate Governance and Industrial Organization", The Yale Law Journal, vol. 102 No 4: pp. 871-906.

Gilson, Ronald J. (2006): "Controlling Shareholders and Corporate Governance: Complicating the Comparative Taxonomy”, Harvard Law Review, vol. 119 No6: pp. 16411679.

GiLson, Ronald J. (2007): "Controlling Family Shareholders in Developing Countries: Anchoring Relational Exchange”, Stanford Law Review, vol. 60 No 2: pp. 633-655.

Gilson, Ronald J., Sabel, Charles y Scott, Robert (2009): "Contracting for Innovation: Vertical Disintegration and Interfirm Collaboration”, Columbia Law Review, vol. 109 No 3: pp. 431-502.

Gilson, Ronald J. y Milhaupt, Curtis J. (2011): "Economically Benevolent Dictators: Lessons for Developing Democracies", American Journal of Comparative Law, vol. 59 No 1: pp. 227-288.

Gilson, Ronald J. y Milhaupt, Curtis J. (2008): “Sovereign Wealth Funds and Corporate Governance: A Minimalist Response to the New Mercantilism”, Stanford Law Review, vol. 60 .

Goergen, Marc et al. (2005): "Corporate Governance Convergence: Evidence from Takeover Regulation Reforms in Europe", Oxford Review of Economic Policy, vol. 21.

Gordon, Jeffrey N. (2004): "The International Relations Wedge in the Corporate Convergence Debate”, en Gordon, Jeffrey N. y Roe, Mark J. (edit.), Convergence and Persistence in Corporate Governance (Cambridge, Cambridge University Press).

Hahn, Donghoon y Lee, Keun (2006): "Chinese Business Groups: Their Origins and Development”, en Chang, Sea-Jin (edit.), Business Groups in East Asia: Financial Crisis, Restructuring, and New Growth (New York, Oxford University Press).

Hall, Peter y Soskice, David (edit.) (2001): Varieties of Capitalism: The Institutional Foundations of Comparative Advantage (New York, Oxford University Press).

Hansmann, Henry y Kraakman, Reinier (2004): “The End of History for Corporate Law”, Convergence and Persistence in Corporate Governance.

Hermert Smith LLP (2011): "Chinese State-Owned Enterprises Under the Microscope: Increased Antitrust Scrutiny by the EU and Chinese Authorities”, Disponible en: 
<www.herbertsmithfreehills.com/-/media/HS/L-031011-5.pdf.> [fecha de consulta: 7 de junio de 2013]

Howson, Nicholas (2009): "China's Restructured Commercial Banks: Nomenklatura Accountability Serving Corporate Governance Reform?” en ZHU, Min; CAI, Jinging y Avery, Martha (edit.), China's Emerging Financial Markets: Challenges and Global Impact (Singapur, John Wiley \& Sons (Asia) Pte. Ltd.) pp. 123-163.

Hu, Jintao (2007): "Report in the Seventeenth General Meeting of the Communist Party of China" Disponible en: <http://cpc.people.com.cn/GB/104019/104099/6429414. html> [fecha de consulta: 7 de junio de 2013].

Hu, Zongliang y Zang, Wei (2005): Jituan Gongsi Zhanlue: Zhiding, Shishi yu Pingjia [Group Companies' Strategies: Analysis, Implementation and Evaluation] (Beijing, Tsinghua University Press, Ltd.).

Huang, Yasheng (2008): Capitalism with Chinese Characteristics: Entrepreneurship and the State (New York, Cambridge University Press).

Huang, Chi-Wei (2008): "Worldwide Corporate Convergence within a Pluralistic Legal Order: Company law and the Independent Director System in Contemporary China", Hastings International and Comparative Law Review, vol. 31 No 1: pp. 361-436.

Keister, Lisa A. (1998): "Engineering Growth: Business Group Structure and Firm Performance in China's Transition Economy”, American Journal of Sociology, vol. 104 No 2: pp. 404-440.

Keister, Lisa A. (2009): "Interfirm Relations in China: Group Structure and Firm Performance in Business Groups”, American Behavioral Scientist, vol. 52 No 12: pp. 17091730 .

Knowledge@Wharton (2012): "Shrouded in Mystery: Chinese Executive Compensation and the Numbers behind the Number", Arabic Knowledge@Wharton, 14 de marzo de 2012. Disponible en: http://knowledge.wharton.upenn.edu/arabic/article. cfm?articleid=2824 [fecha de consulta: 7 de noviembre de 2012].

La Porta, Rafael et al. (1998): "Law and Finance", Journal of Political Economy, vol. 106 No6: pp. 1113-1155.

Levy, Clifford J. (2009): “Chinese Communist Party, Russia’s Rulers See a Role Model for Governing", The New York Times, 18 de octubre de 2009.

LI, Peng (2011): "Yangqi ru yue chaoyong" [The Influx of the Central SOEs into Guandong], Caijing guojia zhoukan [Economy \& Nation Weekly], Vol. 7, 4 de abril de 2011. Disponible en: <http://www.ennweekly.com/2011/0404/2123.html> [fecha de consulta: 3 de enero de 2013].

Li, Rongrong (2010): "Central-Enterprise Executives Average Annual Salary of About 600,000”. Disponible en: <http://politics.people.com.cn/GB/1027/10736395.html> [fecha de consulta: 7 de junio de 2013].

Lieberthal, Kenneth (2004): Governing China: From Revolution Through Reform (New York, W. W. Norton \& Company, Inc., segunda Edición).

LIN, Li-Wen (2007): "Corporate Social Accountability Standards in the global supply Chain: Resistance, Reconsideration, and Resolution in China”, Cardozo Journal of International \& Comparative Law, vol. 15 No 2: pp. 321-372. 
Lin, Li-Wen (2009): "Legal Transplants through Private Contracting: Codes of Vendor Conduct in Global Supply Chains as an Example", American Journal of Comparative Law, vol. 57 No 3: pp. 711-746.

Lin, Li-Wen (2010): "Corporate Social Responsibility in China: Window Dressing or Structural Change?”, Berkeley Journal of International Law, vol. 28 No 1: pp. 64-102.

Lin, Nan (2011): "Capitalism in China: A Centrally Managed Capitalism (CMC) and Its Future", Management \& Organization Review, vol. 7.

Liu, Chengwei (2008): Chinese Company And Securities Law: Investment Vehicles, Mergers And Acquisitions And Corporate Finance In China (Holanda, Kluwer Law International) $425 \mathrm{pp}$.

Liu, Lan-Lan (2012): “Zhongguo Qiye 500 Qiang Guoqi Zhan Juedui Youshi Lirun Shi Minqi Qibei” [500 Chinese State-Owned Enterprises Dominate the Profits of the Private Sector by Over Seven Times], Tengxun Caijing [Tencent Finance \& Economics], 3 de septiembre de 2012. Disponible en: <http://finance.qq.com/a/20120903/000473.htm> [fecha de consulta: 20 de mayo de 2013].

Ma, Hengyun y Oxley, Les (2012): China's Energy Economy (Berlín, Springer) 291 pp.

MacMahon, Dinny y Ackerman, Andrew (2011): "SEC Wrestles with China", The Wall Street Journal, 10 de septiembre de 2011. Disponible en: <http://online.wsj.com/article/SB10001424053111904103404576560320138101738.html> [fecha de consulta: 5 de enero de 2013].

Martin, Michael F. (2012): “China’s Banking System: Issues for Congress”, Reporte del Congressional Research Service, 20 de febrero de 2012.

Mattlin, Mikael (2011): "Whose Money? The Tug-of-War over Chinese State Enterprise Profits", Fiia Briefing Paper, No 79, abril de 2011 (Helsinki, The Finnish Institute of International Affairs). Disponible en: <http:/www.fiia.fi/en/publication/181/whose_ money/> [fecha de consulta: 5 de enero de 2013].

Mauzy, Diane K. y Milne, R.S.(2002): Singapore Politics Under the People's Action Party. Disponible en: < http://www.untag-smd.ac.id/files/Perpustakaan_Digital_2/POLITICS\%20AND\%20GOVERNMENT\%20Singapore\%20Politics\%20Under $\% 20$ the\%20People\%92s\%20Action\%20Party.pdf> [fecha de consulta: 5 de enero de 2013].

MeYer, Marshall W. (2011): “Is it Capitalism?” Management \& Organization Review, vol. 7 No 1: pp. 5-18.

McGregor, Richard (2010): The Party: The Secret World of China's Communist Rulers (New York, HarperCollins Publishers).

Milhaupt, Curtis J. (1998): "Property Right in Firms", Virginia Law Review, vol. 84 No 6: pp. 1145-1194.

Milhaupt, Curtis J. (2002): “On the (Fleeting) Existence of the Main Bank System and Other Japanese Economic Institutions”, Law \& Social Inquiry, vol. 27 No 2: pp. 425436.

Milhaupt, Curtis J. y Pistor, Katharina (2008): Law and Capitalism: What Corporate Crisis Reveal about Legal Systems and Economic Development around the World (Chicago, The University of Chicago Press). 
Milhaupt, Curtis J. (2009): “Is the U.S. Ready for FDI from China? Lessons from Japan's Experience in the 1980s", en Sauvant, Karl P. (edit.), Investing in the United States: Is the U.S. ready for FDI from China? (Cheltelham, Inglaterra, Edward Elgar Publishing Limited) pp. 185-208.

Miwa, Yoshiro y Ramseyer, Mark (2006): The Fable of the Keiretsu (Chicago, The University of Chicago Press).

Morck, Randall y Nakamura, Masao (2007): "Business Groups and the Big Push: Meiji Japan's Mass Privatization and Subsequent Growth", Enterprise \& Society, vol. 8 No 3: pp. 543-601.

Naughton, Barry (2008): "SASAC and Rising Corporate Power in China”, China Leadership Monitor, Vol. 24, marzo de 2008 (Stanford, Hoover Institution). Disponible en: <http://www.hoover.org/publications/china-leadership-monitor/article/5668> [fecha de consulta: 5 de enero de 2013].

Nolan, Peter y Wang, Xiaoqiang (1999): "Beyond Privatization: Institutional Innovation and Growth in China’s Large State-Owned Enterprises”, World Development, vol. 27 No 1: pp. 169-200.

OCDE (2009): OECD Working Group on Privatisation \& Corporate Governance of StateOwned Assets, State-Owned Enterprises in China: Reviewing the Evidence.

Olson, Mancur (1982): The Rise and Decline of Nations (New Haven, Yale University Press) 273 pp.

Pargendler, Mariana (2012): "State Ownership and Corporate Governance", Fordham Law Review, vol. 80 No 6: pp. 2917-2973.

Qian, Yingyi (1994): “Financial System Reform in China: Lessons from Japan's Main Bank System”, en Aoki, Masahiko y Patrick, Hugh (edit.), The Japanese Main Bank System: Its Relevance to Developing and Transforming Economies (New York, Oxford University Press) pp. 552-591.

Rajan, Raghuram G. y Zingales, Luigi (2003): "The Great Reversals: The Politics of Financial Development in the Twentieth Century", Journal of Financial Economics, vol. 69 No1: pp. 5-50.

Roe, Mark J. (1994): Strong Managers, Weak Owners: The Political Roots of American Corporate Finance (Princeton, Princeton University Press).

Roy, William G. (1997): Socializing Capital: The Rise of the Large Industrial Corporation in America (Princeton, Princeton University Press).

Szamosszegi, Andrew y Kyle, Cole (2011): An Analysis of State-Owned Enterprises and State Capitalism in China (Seattle, CreateSpace Independent Publishing Platform).

SASAC (2003): "Principales funciones y responsabilidades de SASAC" (Beijing, SASAC). Disponible en: <http://www.sasac.gov.cn/n2963340/n2963393/2965120.html> [fecha de consulta: 23 de marzo de 2013].

SASAC (2004): China's State-Owned Assets Supervision and Administration Yearbook 2004 (Beijing, China Economic Publishing House).

SASAC (2006): Notice on the Work of Nominating the Party's 17th National Congress Members Representing the Central Enterprise System (Beijing, China Economic Publishing House). 
SASAC (2008): China's State-Owned Assets Supervision and Administration Yearbook 2008

(Beijing, China Economic Publishing House).

SASAC (2010a): China Enterprise Management Annual (Beijing, Enterprise Management Publishing House).

Sasac (2010b): China's State-Owned Assets Supervision and Administration Yearbook 2010 (Beijing, China Economic Publishing House).

SASAC (2010c): Almanac of Finance Companies of Chinese Business Groups (Beijing, China Financial Publishing House).

SASAC (2010d): Individual Operation Conditions of Central Enterprises (Beijing, China Financial Publishing House).

Shambaugh, David (2008): “Training China's Political Elite: The Party School System”, The China Quarterly, vol. 196, diciembre de 2008: pp. 827-844.

Schuman, Michael (2011): “Is China Facing a Japanese future?”, Time Business \& Money (New York, Time Inc.). Disponible en: <http://business.time.com/2011/02/14/is-chinafacing-a-japanese-future/> [fecha de consulta: 5 de enero de 2013].

Sheard, Paul (1989): “The Main Bank System and Corporate Monitoring and Control in Japan”, Journal of Economic Behavior \& Organization, Vol. 11 No 2: pp. 399-422.

SHI, Xiping (2007): Declaración del Sr. Xiping Shi (Jefe de la Oficina de Personal de SASAC). Comunicado de Prensa de la Oficina de Personal de SASAC, 21 de junio de 2007.

Sklar, Martin J. (1988): The Corporate Reconstruction of American Capitalism, 1890-1916: The Market, The Law and Politics (Cambridge, Cambridge University Press).

The Economist (2011a): "Bamboo Capitalism" (Cover story). Editorial. The Economist, 12 de marzo de 2011: p. 13.

The Economist (2011b): "Let a Million Flowers Bloom", The Economist, 12 de marzo de 2011: pp. 79-81.

Quinney, James, Fountoukakos, Kyriakos, Jephсотт, Mark, Zhang, Angela, Ip, Karen y TAM, Betty (2011): "Chinese state-owned enterprises under the microscope: Increased antitrust scrutiny by the EU and Chinese authorities", Herbert Smith Competition, Regulation and Trade e-bulletin, 3 de octubre de 2011. Disponible en: <http://www. herbertsmithfreehills.com/-/media/HS/L-031011-5.pdf> [fecha de consulta: 6 de enero de 2013].

TAN, Wei (2012): "SOEs and Competition Policy in China”. Disponible en: <https://www. competitionpolicyinternational.com/assets/Columns/cpi-asia-antitrust-column-tanFINAL.pdf> [fecha de consulta: 3 de enero de 2013].

TANG, Xing (2008): "Protecting Minority Investors in China: A Task for Both Legislation and Enforcement", en Kanda, Hideki; Kim, Kon-Sik; y Milhaupt, Curtis J. (edit.), Transforming Corporate Governance in East Asia (Abingdon, Inglaterra, Routledge) pp. $141-163$.

Temasek (2012): “Temasek Review 2012”. Disponible en: <http://www.temasekreview. com.sg/governance/governance_framework.aspx> [fecha de consulta: 19 de octubre de 2012]. 
Tsai, Kellee S. (2002): Back-Alley Banking: Private Entrepreneurs in China (Ithaca, Cornell University Press, Primera Edición).

Unirule Institute Of Economics (2011): The Nature, Performance and Reform of StateOwned Enterprises (Beijing, Unirule Institute of Economics).

United States - China Economic and Security Review Commission (2011), "Report to Congress". Disponible en: <http://www.uscc.gov/annual_report/2011/annual_report_full_11.pdf> [fecha de consulta: 27 de diciembre de 2012].

Walder, Andrew G. (2011): "From Control to Ownership: China's Managerial Revolution”, Management \& Organization Review vol. 7.

Walter, Carl E. y Howie, Fraser J.T. (2011): Red Capitalism: The Fragile Financial Foundation of China's Extraordinary Rise (Singapur, John Wiley \& Sons (Asia) Pte. Ltd).

Webi, Sara (2007): Temasek's Chief, Ho Ching, Likes to Take Risks. Disponible en: < http:// www.nytimes.com/2007/07/27/business/worldbusiness/27iht-temasek.1.6862331. html> [fecha de consulta: 7 de junio de 2013].

WitT, Michael A. (2010): “What Variety of Capitalism?”, INSEAD Faculty \& Research Working Paper, No 2010/88/EPS. Disponible en: <http://papers.ssrn.com/sol3/papers. cfm?abstract_id=1695940> [fecha de consulta: 3 de enero de 2013].

Witt, Michael y Redding, Gordon (2013): "China: Authoritarian Capitalism”, Disponible en: <http://papers.ssrn.com/sol3/papers.cfm?abstract_id=2171651> [fecha de consulta: 3 de enero de 2013].

Wu, Yue (2003): Qiye Jituan Fali Yanjiu [Investigación sobre la Teoría Jurídica de los Grupos Empresariales] (Beijing, Law Press).

Xinhua News (2012): "Anshan Iron and the Establishment of the Board of Directors of 51 of China's Central Enterprises” Disponible en: <http://big5.xinhuanet.com/gate/ big5/news.xinhuanet.com/fortune/2012-12/31/c_124169718.htm> [fecha de consulta: 7 de junio de 2013].

Zhang, Angela Huyue (2011): "The Enforcement of the Anti-Monopoly Law in China: An Institutional Design Perspective". Disponible en: <http://papers.ssrn.com/sol3/papers.cfm?abstract_id=1783037> [fecha de consulta: 7 de noviembre de 2012].

Zheng, Wentong (2009): “China's Antimonopoly Law - One Year Down Part 5. A De Facto "Dual - Track" Competition Regime?”. Disponible en: <http://lawprofessors.typepad.com/antitrustprof_blog/2009/12/chinas-antimonopoly-lawone-year-down-part5-a-de-facto-dualtrack-competition-regime-.html> [fecha de consulta: 29 de septiembre de 2012].

Zheng, Haihang, QI, Yudong y Wu, Dongmei (2009): Guoyou Zichan Guanli Tizhi yu Guoyou Konggu Gongsi Yanjiu [Administración de los Activos del Estado y de las Sociedades Controladas por el Estado] (Beijing, Economy \& Management Publishing House).

\section{JURISPRUDENCIA CITADA}

\section{CHINA:}

Huna Zheqin Group Co. Ltd. con Chendu Yinghua Investment Co. Ltd., Corte de Apelaciones de Huaihua, 27 de mayo de 2009, Caso Civil No 6. 
Zhang Buo con Beijing Jing Gong Garments Group Co. Ltd. (2009) Corte de Apelaciones de Pekín, 20 de mayo de 2009, Caso Civil No 2985.

Comisión Europea:

China National Bluestar con Elkem (2011): Case No COMP/M.6082 - CHINA NATIONAL BLUESTAR/ ELKEM Notification of 24/02/2011 pursuant to Article 4 of Council Regulation No 139/2004, Comisión Europea, 31 de marzo de 2011 (Procedimiento de Fusiones). Disponible en: <http://ec.europa.eu/competition/mergers/cases/decisions/ m6082_20110331_20310_1967334_EN.pdf> [fecha de consulta: 6 de enero de 2013]. DSM/Sinochem/JV (2011): Case No COMP/M.6113 DSM/Sinochem/JV, Commission decision pursuant to Article 6(1)(b) of Council Regulation No 139/2004, Comisión Europea, 19 de mayo de 2011 (Procedimiento de Fusiones). Disponible en: <http://ec.europa. eu/competition/mergers/cases/decisions/m6113_20110519_20310_1812856_EN.pdf> [fecha de consulta: 6 de enero de 2013].

EsTADOS UNIDOS:

U.S. v. Aguilar, 783 F. Supp. 2d 1108, 1109-10 (C.D. Cal. 2011).

U.S. v. Carson, et al., No 09-77 (C.D. Ca. 2009). Disponible en: <http://fcpa.shearman. $\mathrm{com} /$ ?s=matter\&mode=form\&id=208> [fecha de consulta: 5 de enero de 2013].

U.S. v. Noriega, et al., No 10-1031 (C.D. Ca. 2010). Disponible en: <http://fcpa.shearman.com/?s=matter\&mode=form\&id=363> [fecha de consulta: 5 de enero de 2013].

\section{NORMAS CITADAS}

CHINA:

Documento No 8 de 1987 del Consejo de Estado sobre Guanyu Tuijin Keyan Sheji Danwei Jinru Da Zhong Xing Gongye Qiye de Guiding [Reglas sobre la Promoción de Centros Científicos y de Diseño para ser Incluidos en Empresas Grandes y Medianas].

Documento No 71 de 1991 del Consejo de Estado de China sobre Guanyu Xuanze Yipi Daxing Qiye Jituan Jinxing Shidian de Qingshi [Instrucciones sobre la Selección de un Grupo de Grandes Grupos Empresariales para Experimentación].

Documento No 15 de 1997 del Consejo de Estado de China sobre Qiye Jituan Dengji Guanli Zhanxing Guiding [Reglas Provisionales sobre el Registro de los Grupos Empresariales].

Documento No 17 de 2009 del Departamento de Organización del Partido Comunista de China sobre Medidas Concernientes a la Evaluación Integrada de los Altos Equipos Administrativos y Altos Ejecutivos de las Empresas Centrales (Provisional).

Ley antimonopolio de la República Popular China del 30 de agosto de 2007.

Ley de Activos de SOEs del 28 de octubre de 2008.

Ley de Sociedades del 1 de enero de 2006.

Medidas Administrativas para las Sociedades Financieras de los Grupos Empresariales del 27 de julio de 2004, modificadas el 28 de octubre de 2006, de la Comisión China Reguladora de Bancos. 
Milhaupt, Curtis J. / Lin, Li-Wen — "Los grandes grupos empresariales chinos: ...”

Opiniones del 16 de diciembre de 1987 de la Comisión de Reforma del Sistema Económico Nacional y la Comisión Nacional Económica sobre Guanyu Zujian he Fazhan Qiye Jituan de Jidian Yijian [Varias opiniones sobre la Construcción y Desarrollo de los Grupos Empresariales].

Reglas Generales sobre Préstamos del 28 de junio de 1996 del Banco Popular Chino.

\section{Estados Unidos:}

Código de los Estados Unidos [United States Code, U.S.C.], 50 U.S.C. app. $\$ 2170$ (2000).

Ley sobre Seguridad Nacional en Relación con la Inversión Extranjera de 2007 [Foreign Investment and National Security Act of 2007 (Pub.L. 110-49, 121 Stat. 246), promulgada el 26 de julio 2007]. 